Check for updates

Cite this: RSC Adv., 2018, 8, 34331

Received 4th June 2018

Accepted 1st October 2018

DOI: $10.1039 / c 8 r a 04773 a$

rsc.li/rsc-advances

\section{Semi-synthesis, structural modification and biological evaluation of 5-arylbenzofuran neolignans $\uparrow$}

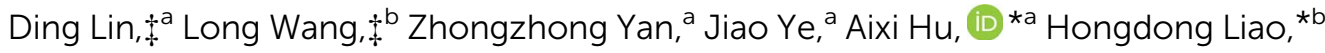 \\ Juan Liuc and Junmei Peng ${ }^{c}$
}

5-Arylbenzofuran neolignans, a newfound class of natural products, were reported to possess several kinds of pharmacological activities. To solve the lack of natural sources and promote the research of 5arylbenzofuran neolignans in all fields, an available semi-synthesis methodology of 5-arylbenzofuran neolignans was developed, and a detailed structural modification was conducted. In the meantime, a one-pot process of Waker-type cyclization and Wacker-type oxidation was developed. To explore the potential of 5-arylbenzofuran neolignans as bioactive substances, 5-arylbenzofuran neolignans and their derivatives were evaluated for their cytotoxicity. As a result, a preliminary structure-activity relationship was obtained. Most derivatives revealed low cytotoxic effects suggesting that they were relatively safer than the natural 5-arylbenzofuran neolignan. Several derivatives showed high cytotoxicities which were found to be closely associated with apoptosis-inducing. The selectivity assay for cytotoxicity showed tumor cells were more sensitive to the promising compounds than normal cells.

\section{Introduction}

Neolignans are a large class of natural products, which consist of two propylbenzene $\left(\mathrm{C}_{6} \mathrm{C}_{3}\right)$ units. ${ }^{1}$ Benzofuran neolignans, a significant kind of neolignans, have drawn great interest due to their special skeleton and pharmacological activities. So far, the research of benzofuran neolignans has mainly focused on 2arylbenzofuran neolignans (Fig. 1). Lots of 2-arylbenzofuran neolignans, such as ailanthoidol, ${ }^{2}$ eupomatenoid $7,{ }^{3}$ licarin $\mathrm{A}^{4}$ and acuminatin, ${ }^{5}$ have been proved to possess excellent biological activities.

In recent years, some 5-arylbenzofuran neolignans (Fig. 1) have come into sight with favorable anti-inflammatory, ${ }^{6,7}$ anti-microbial, ${ }^{8}$ and anti-influenza activities. ${ }^{9}$ Due to the difference in the bonding position of the two aromatic rings, 5-arylbenzofuran neolignans may have quite different biological effects compared to 2-arylbenzofuran neolignans. However, the low content in natural products and the difficulty of chemical synthesis have blocked the research and development of 5-arylbenzofuran neolignans.

${ }^{a}$ College of Chemistry and Chemical Engineering, Hunan University, Changsha 410082, China. E-mail: linding@hnu.edu.cn; yzz1990@hnu.edu.cn; yejiao@hnu. edu.cn; axhu@hnu.edu.cn

${ }^{b}$ College of Biology, Hunan University, Changsha 410082, China. E-mail: 263729738@ qq.com; liaohongdong@126.com

${ }^{c}$ College of Pharmacy and Biological Science, University of South China, Hengyang 421000, China.E-mail:810408277@qq.com; pengmarina@126.com

$\dagger$ Electronic supplementary information (ESI) available: ${ }^{1} \mathrm{H}$ NMR, ${ }^{13} \mathrm{C}$ NMR. See DOI: $10.1039 / \mathrm{c} 8 \mathrm{ra} 04773 \mathrm{a}$

$\$$ These authors contributed equally to this work.
In order to solve the problem of a lack of a natural source of 5arylbenzofuran neolignans, we developed a semi-synthesis methodology utilizing honokiol, a high-yield natural product whose total synthesis methodologies are various, as the starting material (Fig. 1). To promote the study of 5-arylbenzofuran neolignans in all fields, we made structural modification and investigated their cytotoxicity. In addition, inspired by the achievements of 2-arylbenzofuran neolignans in tumor therapy, ${ }^{\mathbf{1 0}} 5$-arylbenzofuran neolignan derivatives with high cytotoxicities were further evaluated for their anti-proliferative effects and mechanisms.

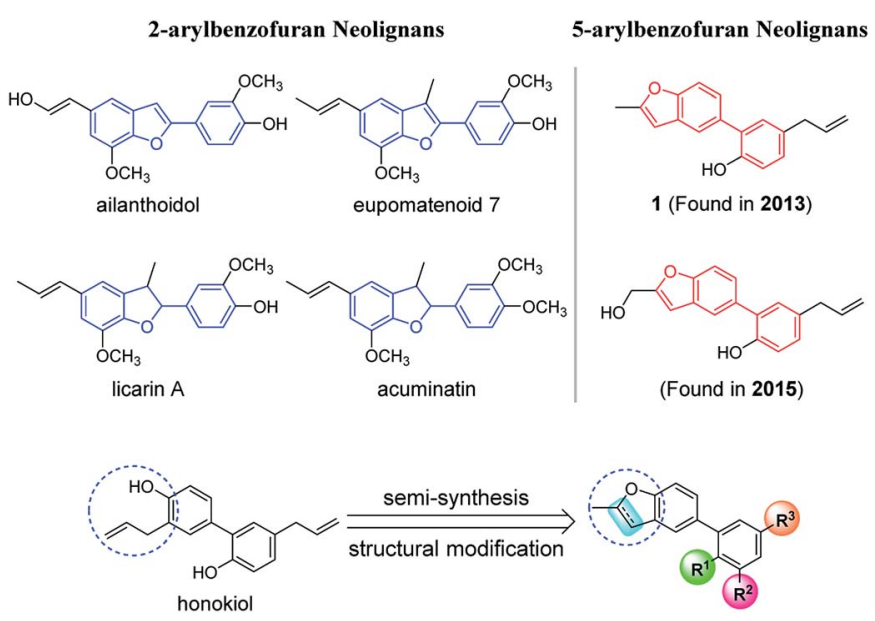

Fig. 1 The comparison of 5-arylbenzofuran neolignans with 2-arylbenzofuran neolignans, and the semi-synthesis methodology and structural modification of 5-arylbenzofuran neolignans. 


\section{Results and discussion}

\section{Chemistry}

It is of great difficulty to totally synthesize 5-arylbenzofuran neolignans because the two propylbenzene units are directly connected by benzenes. Nonetheless we found there are a number of natural products containing the structure of 2-allyl4-arylphenol which could be intramolecularly cyclized to afford 5 -arylbenzofuran neolignans. In this paper, honokiol, a highyield natural product with the structure of 2-allyl-4-arylphenol, was selected as the starting material (Scheme 1).

5-Arylbenzofuran neolignan $\mathbf{1}$, which can only be extracted from natural product before, ${ }^{6}$ was synthesized starting from honokiol by Wacker-type intramolecular cyclization ${ }^{11}$ in a high yield. For investigating the influence by furan ring, dihydrofuran derivative 2 was prepared through acid catalytic cyclization from honokiol in the presence of concentrated sulfuric acid. ${ }^{12}$ To discuss the effects of phenolic hydroxyl and allyl group, we synthesized 3-5 by the method depicted in Scheme 1. Compound 3 and $\mathbf{4}$ were obtained by hydrogenation reduction of $\mathbf{1}$ using $\mathrm{NaBH}_{4}$ (ref. 13) or $\mathrm{H}_{2}$ (ref. 14) as hydrogen source respectively, while compound $\mathbf{5}$ was generated via the etherification of $\mathbf{1}$.

In order to study the influences by different substituents on benzene ring, compound 7-26 with diverse substituents were designed and prepared. Among them, compounds 6-10 and 20$\mathbf{2 4}$ were synthesized from $\mathbf{1}$ according to the method described in Scheme 2. The bromination reaction of $\mathbf{1}$ provided compound 7 using NBS as the brominating reagent ${ }^{15}$ and the nitration of $\mathbf{1}$ prepared compound $\mathbf{8}$ by classic procedure. Compound 10 was synthesized via reduction reaction with zinc powder as a catalyst from $\mathbf{9}$, which was prepared by nitrosation from 1. Compounds 20-24 were obtained through Mannich reaction of $\mathbf{1}$ with formalin and appropriate secondary amines. ${ }^{\mathbf{1 6}}$ And compound $\mathbf{6}$ was generated by hydrogenation reduction of 20 catalyzed by palladium-carbon.

Compounds 11-19, 25 and 26 were prepared from 10 according to the approach presented in Scheme 3. Compound $\mathbf{1 1}$ was produced via methylation of 10. Acylamides 12-14 were obtained from $\mathbf{1 0}$ by acylation reaction with acetic anhydride, acryloyl chloride or chloroacetyl chloride, respectively. Aminoacetamides 15-18 were synthesized through reaction between compound 14 and appropriate secondary amines. ${ }^{17}$ Lactams 25 and 26 were prepared by treatment of $\mathbf{1 0}$ with chloroacetyl chloride $^{18}$ or oxalyl chloride ${ }^{19}$ in the presence of 4-dimethylaminopyridine and triethylamine in THF, respectively.

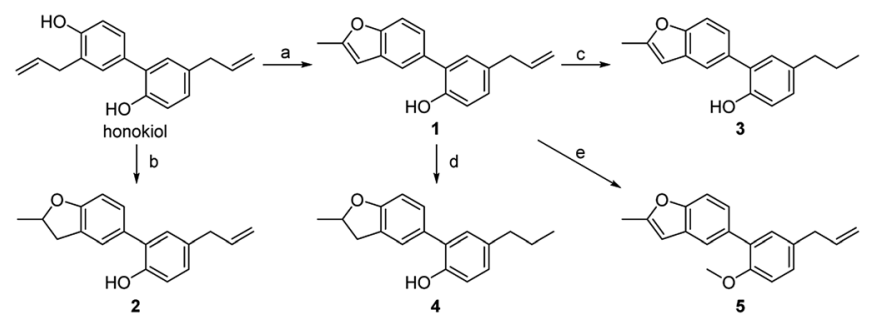

Scheme 1 Reagents and conditions: (a) $\mathrm{PdCl}, \mathrm{NaOAc}, \mathrm{O}_{2}, \mathrm{DMA} / \mathrm{H}_{2} \mathrm{O}$, $60{ }^{\circ} \mathrm{C}$; (b) $\mathrm{H}_{2} \mathrm{SO}_{4}, \mathrm{DCE}, 50{ }^{\circ} \mathrm{C}$; (c) $\mathrm{NaBH}_{4}, \mathrm{NiCl}_{2} \cdot 6 \mathrm{H}_{2} \mathrm{O}$, EtOH, r.t.; (d) $\mathrm{Pd} / \mathrm{C}, \mathrm{H}_{2}, \mathrm{MeOH}$, reflux; (e) $\mathrm{CH}_{3} \mathrm{l}, \mathrm{KOH}$, THF, r.t.

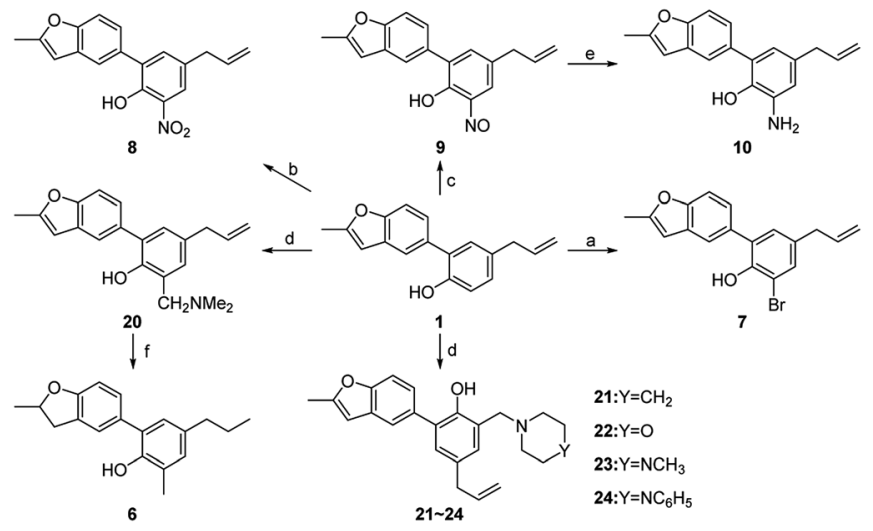

Scheme 2 Reagents and conditions: (a) NBS, MeCN, r.t.; (b) $\mathrm{HNO}_{3}$, $\mathrm{HOAC}, \mathrm{CH}_{2} \mathrm{Cl}_{2}, 0^{\circ} \mathrm{C}$; (c) $\mathrm{NaNO}_{2}$, concentrated hydrochloric acid (36$38 \%$ ), $\mathrm{MeCN} / \mathrm{H}_{2} \mathrm{O}$, r.t.; (d) secondary amines, $\mathrm{HCHO}(37 \%), \mathrm{MeOH}$, $60{ }^{\circ} \mathrm{C}$; (e) $\mathrm{Zn}, \mathrm{NH}_{4} \mathrm{Cl}, \mathrm{HOAc}, \mathrm{EtOH} / \mathrm{H}_{2} \mathrm{O}$, r.t.; (f) $\mathrm{Pd} / \mathrm{C}, \mathrm{H}_{2}, \mathrm{MeOH}$, reflux.

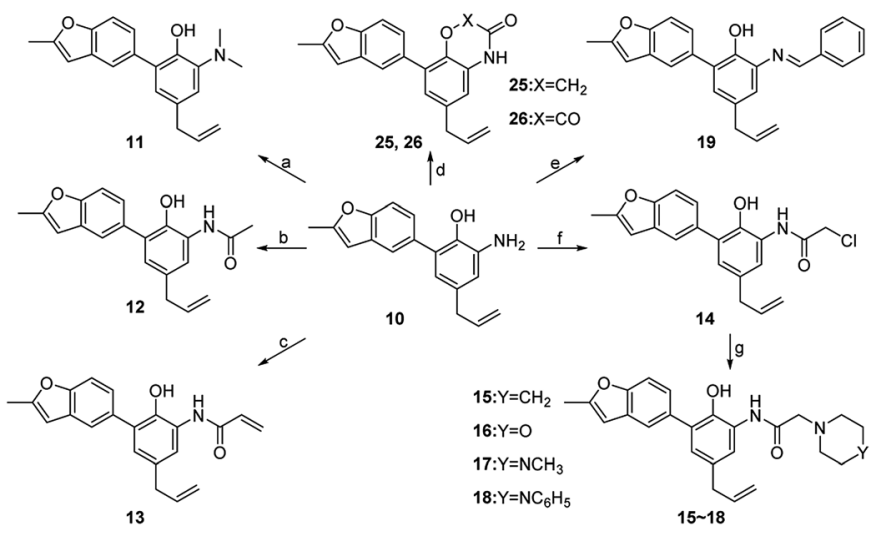

Scheme 3 Reagents and conditions: (a) $\mathrm{CH}_{3}$ l, $\mathrm{NaOAc}$, DMF, r.t.; (b) acetic anhydride, $\mathrm{K}_{2} \mathrm{CO}_{3}$, ethyl acetate, r.t.; (c) acryloyl chloride, $\mathrm{K}_{2} \mathrm{CO}_{3}, \mathrm{CH}_{2} \mathrm{Cl}_{2}$, r.t.; (d) chloroacetyl chloride or oxalyl chloride, DMAP, $\mathrm{NEt}_{3}, \mathrm{THF}$, r.t. to reflux; (e) benzaldehyde, acetic acid, EtOH, r.t.; (f) chloroacetyl chloride, $\mathrm{K}_{2} \mathrm{CO}_{3}, \mathrm{CH}_{2} \mathrm{Cl}_{2}$, r.t.; (g) secondary amines, $\mathrm{NEt}_{3}$, THF, r.t.

For further investigation on the influences of side chain, groups with large polarity or steric hindrance were introduced, and compounds 27-32 were synthesized via the route outlined in Scheme 4. Compound 27 was generated from 1 by Wacker oxidation adopting the condition reported previously. ${ }^{\mathbf{1 1}}$ The condensation reaction of $\mathbf{2 7}$ with appropriate primary amines

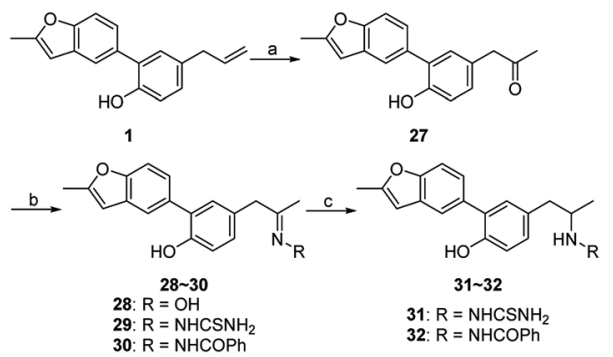

Scheme 4 Reagents and conditions: (a) $\mathrm{PdCl}_{2}, \mathrm{O}_{2}, \mathrm{DMA} / \mathrm{H}_{2} \mathrm{O}, 60{ }^{\circ} \mathrm{C}$; (b) $\mathrm{R}-\mathrm{NH}_{2}$, $\mathrm{EtOH}$, r.t.; (c) $\mathrm{NaBH}_{4}$, EtOH, r.t. 
prepared compounds $28-30,{ }^{20-22}$ and the reduction of 29 and 30 afforded compounds $\mathbf{3 1}$ and 32, respectively. ${ }^{23}$

In the meantime, a one-pot method of Waker-type cyclization and Wacker-type oxidation was developed. The synthetic process was supplied in the Experimental section, and the discussion was provided in the ESI. $\dagger$

\section{Cytotoxicity and SAR analysis}

The cytotoxicity of 5-arylbenzofuran neolignans (1-32) were evaluated via MTT assay against A549 (human lung carcinoma), K562 (human myelogenous leukemia) and HepG2 (human hepatocellular liver carcinoma) tumor cell lines described with $\mathrm{IC}_{50}$ (concentration required for $50 \%$ inhibition). For a clear view, the $\mathrm{IC}_{50}$ values of tested compounds were presented in Tables 1-3 according to their structural differences. It's found that most derivatives showed no cytotoxic effects against three tumor cell lines $\left(\mathrm{IC}_{50}>128 \mu \mathrm{M}\right)$ which suggested they were relatively safer than the natural 5-arylbenzofuran neolignan. Several compounds, such as 23, 26 and 30, displayed obviously higher cytotoxicity than the natural 5-arylbenzofuran neolignan 1. In addition, the A549 and K562 cells were more susceptive to 5-arylbenzofuran neolignans than HepG2 and the structural modifications caused appreciable impact on cytotoxicity.

As shown in Table 1, 5-arylbenzofuran 1 and 3 displayed higher cytotoxicity than 5-aryldihydrbenzofuran 2,4 and 6 . The reduction of allyl group made little difference to activity when comparing compound $\mathbf{1}$ and $\mathbf{3}$ with compound $\mathbf{2}$ and $\mathbf{4}$. Phenolic hydroxyl was essential to the cytotoxicity as compound 5 possessing very low cytotoxicity against three tumor cells. In view of the above results, further research was carried out around the substructure of 5-(phenol-2-yl)benzofuran due to its comparatively good anti-proliferative activity.

In order to discuss the influences by substituents on benzene ring, compounds 7-26 were evaluated for the cytotoxicities and

Table 1 IC $_{50}$ values of compounds 1-6 against HepG2, A549 and K562 cell lines

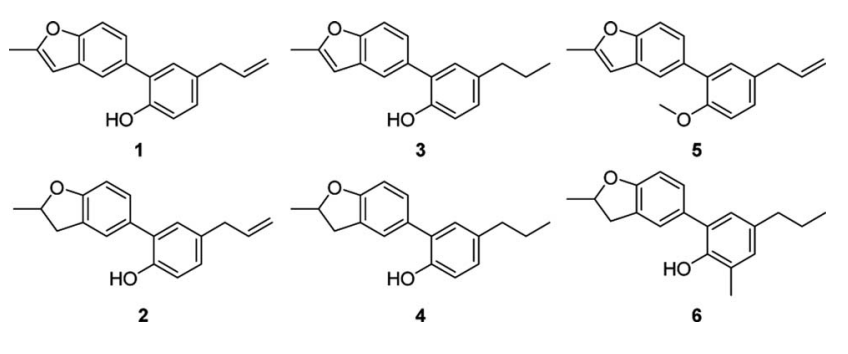

\begin{tabular}{llll}
\hline & $\mathrm{IC}_{50}(\mu \mathrm{M})$ & & \\
\cline { 2 - 4 } Compd. & $\mathrm{A} 549$ & $\mathrm{~K} 562$ & HepG2 \\
\hline $\mathbf{1}$ & $71.5 \pm 1.94$ & $67.8 \pm 8.3$ & $107.2 \pm 12.7$ \\
$\mathbf{2}$ & $115.5 \pm 2.0$ & $126.2 \pm 1.5$ & $125.6 \pm 2.2$ \\
$\mathbf{3}$ & $61.9 \pm 2.7$ & $73.9 \pm 7.3$ & $88.2 \pm 8.0$ \\
$\mathbf{4}$ & $96.1 \pm 7.0$ & $72.8 \pm 8.9$ & $121.6 \pm 2.5$ \\
$\mathbf{5}$ & $>128$ & $>128$ & $>128$ \\
$\mathbf{6}$ & $84.9 \pm 7.8$ & $102.3 \pm 15.5$ & $>128$
\end{tabular}

the results were displayed in Table 2. Compounds with simple substituents such as bromo, nitro, nitroso, amino and dimethylamino (7-11) showed no cytotoxicity. Acylamides (12-14) seemed to have equipotent cytotoxicity compared to the natural product 1 while aminoacetamides (15-18) showed lower cytotoxicity except substituted by 4-methylpiperazine (17). Similar rule appeared in

Table $2 \quad I C_{50}$ values of compound 7-26 against HepG2, A549 and K562 cell lines

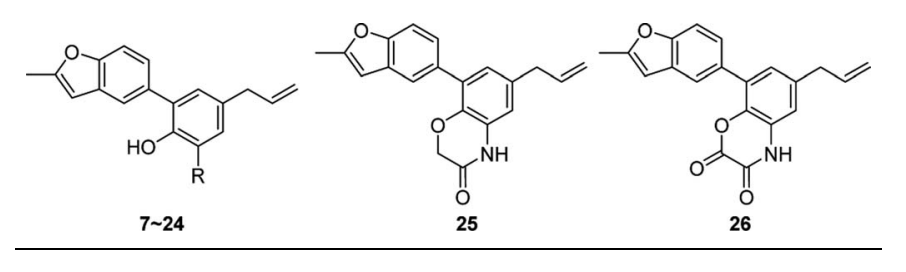

\begin{tabular}{|c|c|c|c|c|}
\hline \multirow[b]{2}{*}{ Compd. } & \multirow[b]{2}{*}{$\mathrm{R}$} & \multicolumn{3}{|l|}{$\mathrm{IC}_{50}(\mu \mathrm{M})$} \\
\hline & & A549 & K562 & HepG2 \\
\hline 7 & $\mathrm{Br}$ & $>128$ & $>128$ & $>128$ \\
\hline 8 & $\mathrm{NO}_{2}$ & $>128$ & $>128$ & $>128$ \\
\hline 9 & NO & $>128$ & $>128$ & $>128$ \\
\hline 10 & $\mathrm{NH}_{2}$ & $>128$ & $>128$ & $>128$ \\
\hline 11 & $\mathrm{~N}\left(\mathrm{CH}_{3}\right)_{2}$ & $>128$ & $>128$ & $>128$ \\
\hline 12 & $\mathrm{NHCOCH}_{3}$ & $88.2 \pm 3.4$ & $80.0 \pm 5.1$ & $87.4 \pm 6.1$ \\
\hline 13 & & $53.0 \pm 5.7$ & $34.9 \pm 1.2$ & $63.8 \pm 3.1$ \\
\hline 14 & & $65.0 \pm 2.0$ & $58.5 \pm 0.5$ & $>128$ \\
\hline 15 & & $>128$ & $>128$ & $>128$ \\
\hline 16 & & $>128$ & $>128$ & $>128$ \\
\hline 17 & & $75.4 \pm 2.2$ & $61.2 \pm 5.6$ & $98.5 \pm 7.8$ \\
\hline 18 & & $>128$ & $>128$ & $>128$ \\
\hline 19 & & $>128$ & $>128$ & $>128$ \\
\hline 20 & & $>128$ & $87.78 \pm 13.9$ & $>128$ \\
\hline 21 & & $>128$ & $>128$ & $>128$ \\
\hline 22 & & $>128$ & $>128$ & $>128$ \\
\hline 23 & & $25.1 \pm 4.4$ & $29.6 \pm 2.5$ & $36.8 \pm 0.2$ \\
\hline 24 & & $>128$ & $>128$ & $>128$ \\
\hline 25 & & $53.4 \pm 5.6$ & $41.8 \pm 5.2$ & $>128$ \\
\hline 26 & & $32.4 \pm 1.7$ & $18.0 \pm 2.6$ & $75.4 \pm 0.3$ \\
\hline
\end{tabular}


Table $3 \quad I C_{50}$ values of compound 27-32 against HepG2, A549 and K562 cell lines

\begin{tabular}{|c|c|c|c|c|}
\hline \multirow[b]{2}{*}{ Compd. } & \multirow[b]{2}{*}{$\mathrm{R}^{1}$ or $\mathrm{R}^{2}$} & \multicolumn{3}{|l|}{$\mathrm{IC}_{50}(\mu \mathrm{M})$} \\
\hline & & A549 & K562 & HepG2 \\
\hline 27 & $\mathrm{O}$ & $>128$ & $>128$ & $>128$ \\
\hline 28 & $\mathrm{~N}-\mathrm{OH}$ & $125.1 \pm 12.2$ & $>128$ & $>128$ \\
\hline 29 & & $64.7 \pm 7.4$ & $31.8 \pm 4.4$ & $92.1 \pm 6.2$ \\
\hline 30 & 0 & $22.0 \pm 2.1$ & $29.0 \pm 1.8$ & $26.5 \pm 3.5$ \\
\hline 31 & & $103.8 \pm 5.5$ & $48.1 \pm 3.4$ & $80.9 \pm 1.5$ \\
\hline 32 & & $97.4 \pm 8.0$ & $66.8 \pm 0.7$ & $106.1 \pm 13.6$ \\
\hline $\begin{array}{l}\text { 5-FU }{ }^{a} \\
\text { PTX }^{b}\end{array}$ & & $\begin{array}{l}34.3 \pm 2.1 \\
21.0 \pm 3.0\end{array}$ & $\begin{array}{l}81.9 \pm 7.4 \\
4.6 \pm 0.7\end{array}$ & $\begin{array}{l}>128 \\
16.5 \pm 2.2\end{array}$ \\
\hline
\end{tabular}

mannich bases (20-24), that is the mannich base of 4-methylpiperazine (23) exhibited the highest cytotoxic effect which is much higher than the natural compound 1. Different from compound 5, lactams 25 and 26 showed relatively high cytotoxicity even though neither of their hydroxyl group was free. As a consequence, the structural modifications around phenolic hydroxyl group would have obvious impacts on cytotoxicity.

For further investigation on the modification of side chain, compounds 27-32 were synthesized and their cytotoxicities were exhibited in Table 3. As a result, compounds 29-32 presented higher cytotoxicity than 27 and 28, while 30 showed the highest cytotoxicity. For this position, the introduction of groups with non-polarity or large steric effect may enhance the cytotoxicity.

In addition, the selectivity for cytotoxicity was further studied by testing the cytotoxicity against human umbilical vein endothelial cell (HUVEC). As shown in Table 4, the selectivities of promising compounds 23 and $\mathbf{3 0}$ were 2.02 and 2.50 respectively, which were higher than the positive control paclitaxel. As already

Table 4 The selectivity of promising compounds

\begin{tabular}{llcl}
\hline & \multicolumn{2}{c}{$\mathrm{IC}_{50}(\mu \mathrm{M})$} & \\
\cline { 2 - 3 } Compd. & $\mathrm{A} 549$ & HUVEC & Selectivity $^{a}$ \\
\hline $\mathbf{1}$ & $71.5 \pm 1.94$ & $134.4 \pm 18.8$ & 1.88 \\
$\mathbf{2 3}$ & $25.1 \pm 4.4$ & $50.8 \pm 5.7$ & 2.02 \\
$\mathbf{3 0}$ & $22.0 \pm 2.1$ & $55.1 \pm 6.2$ & 2.50 \\
PTX $^{b}$ & $21.0 \pm 3.0$ & $8.6 \pm 1.6$ & 0.41
\end{tabular}

${ }^{a}$ Selectivity is defined as $\mathrm{IC}_{50}$ (HUVEC)/IC $\mathrm{I}_{50}$ (A549). ${ }^{b}$ PTX: paclitaxel. reported, some human normal cells were more sensitive to paclitaxel than tumor cells, ${ }^{24}$ and it's also a common problem for traditional anticancer drugs. ${ }^{25}$ The promising compounds 23 and 30 seemed to possess certain advantage in the respect.

\section{Morphological analysis}

Microscopic observations were used to investigate the changes of cellular morphology and prove the anti-proliferative activities of compounds with high cytotoxicity. As displayed in Fig. 2A, no apparent changes of cell morphology were observed after HepG2 cells were treated with $20 \mu \mathrm{M}$ of compound 1 for $24 \mathrm{~h}$. However, HepG2 cells treated with compounds 23 and $\mathbf{3 0}$ displayed some morphological changes, such as cell shrinkage, rounding, loss of contact with neighbouring cells and detachment from plate. And the compound 30 had a greater effect on cell morphologies than that of compound 23, which was consistent with their cytotoxicities.

\section{Apoptosis assessment by Hoechst 33258 staining}

In order to observe the changes of the nuclear morphology, the HepG2 cells were stained by Hoechst 33258 and the results were exhibited in Fig. 2B. In the control group it's showed slightly blue and homogeneous fluorescence, and there was no obvious changes of fluorescence in the cells treated with compound $\mathbf{1}$ at the concentration of $20 \mu \mathrm{M}$. However, in the groups treated with 23 or 30, there was a lot of enhanced fluorescence which means karyopyknosis and chromatin condensation in apoptotic cells. It's suggested that compounds 23 and $\mathbf{3 0}$ could induce apoptosis of HepG2.

\section{Apoptosis assessment by flow cytometry analysis}

To clearly analyze the apoptosis-inducing effects of the modified compounds, the apoptosis ratios induced by compound $\mathbf{1}$, 23 and 30 in HepG2 cells were evaluated by flow cytometry analysis (Fig. 3). The result showed that compound $\mathbf{1}$ have little influence on the apoptosis of HepG2 compared with the control group. Compounds 23 and $\mathbf{3 0}$ caused more apoptosis than compound $\mathbf{1}$ at the same concentration, and it was consistent with the results of the Hoechst 33258 staining assay.

\section{mRNA expression in HepG2 cells}

Furthermore, for studying the mechanism of apoptosisinducing caused by modified compounds, the expression levels of mRNAs related to the mitochondria-mediated apoptosis pathway were analyzed by qRT-PCR assay. The mRNA expression levels of caspase-3, caspase-9, Bax, Bcl-2, p53 and $p 21$ in HepG2 cells were displayed in Fig. 4. Caspase-3 and caspase-9 contributes a major role in mitochondria-mediated apoptotic pathway. ${ }^{26}$ And in the HepG2 cells treated with compound 23, the mRNA expression level of caspase-3 and caspase-9 was about twice the level of control group (Fig. 4A), while the mRNA expression level of caspase- 9 and caspase- 3 have no change treated with compound 1 and the caspase-3 expression increased treated with compound $\mathbf{3 0}$. 
A

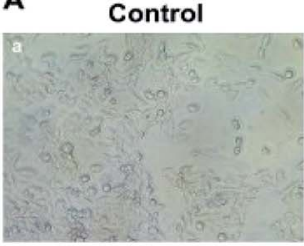

$23(20 \mu \mathrm{M})$

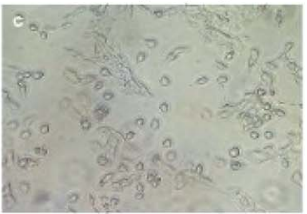

$1(20 \mu \mathrm{M})$

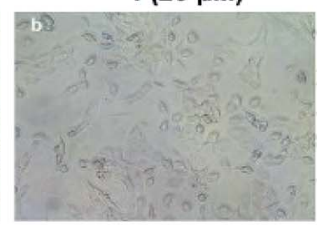

$30(20 \mu \mathrm{M})$

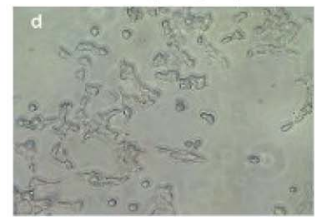

B

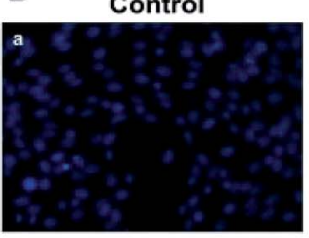

$23(20 \mu \mathrm{M})$

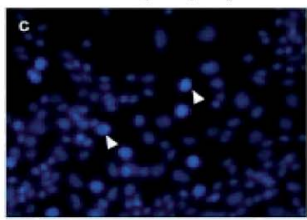

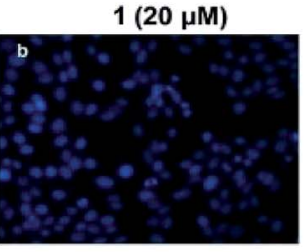

$30(20 \mu \mathrm{M})$

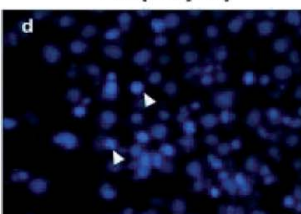

Fig. 2 (A) Cellular morphologies of HepG2 cells treated with different compounds $(1,23,30)$ for 24 h. (B) Images of Hoechst 33258 stained HepG2 cells which were treated with $20 \mu \mathrm{M}$ of different compounds $(1,23,30)$ for $24 \mathrm{~h}$. The arrows indicated the apoptotic cell. Original magnification is $400 x$
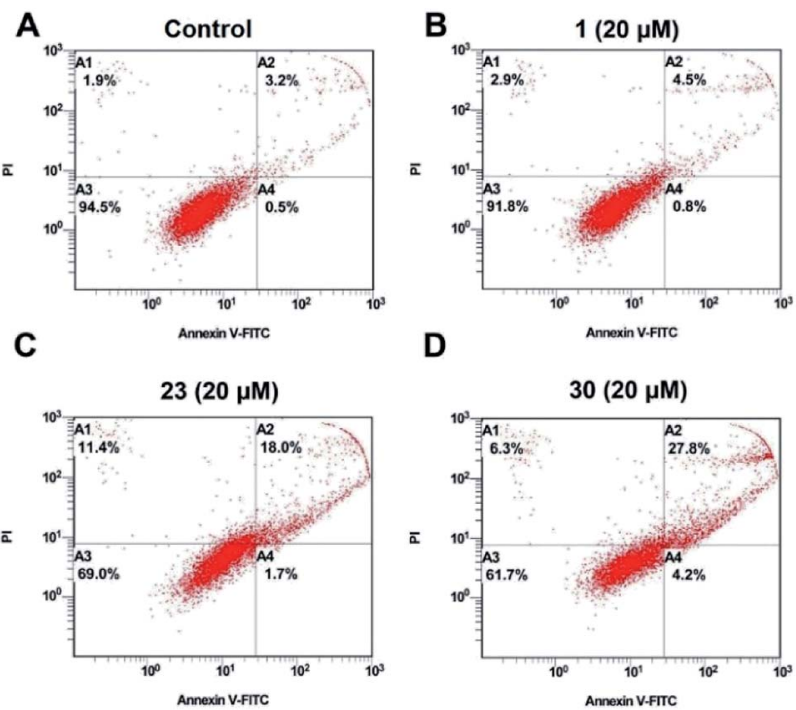

Fig. 3 Apoptosis effect of compounds 1, 23 and 30 at $20 \mu \mathrm{M}$ in HepG2 cells for $24 \mathrm{~h}$. The cells were stained with Annexin V-FITC/P and followed by flow cytometry analysis.

The activation of caspase-dependent apoptosis pathway could be regulated by Bcl-2 family members such as Bax and Bcl-2. ${ }^{27}$ In Fig. 4B, the Bax/Bcl-2 ratio of compound 23 treated HepG2 cells increased obviously, which always resulted in the activation of caspases and led to apoptosis. ${ }^{28}$ However, it made no difference for $\mathrm{Bax} / \mathrm{Bcl}-2$ ratio after treated with compound 1 and $\mathbf{3 0 .}$

In the previous studies, $p 53$ and its downstream gene $p 21$ were also found able to cause apoptosis via the regulation of Bax/Bcl-2 (ref. 29 and 30) and the activation of caspases. ${ }^{31}$ In addition, $p 53$ and $p 21$ played a key role in cell cycle regulation. ${ }^{32}$ As shown in Fig. 4C, the mRNA expression level of $p 53$ and p21 in the HepG2 cells treated with compound 23 were about 2 times higher than the control.

In summary, the compound 23 induces apoptosis of HepG2 cells through the regulation of caspase-dependent p53dependent and Bax/Bcl-2 pathway. However, compound 30 also induce the expression of caspase-3, but had no effect on Bax/Bcl-2 activation pathway. It is suggested that compound $\mathbf{3 0}$ induces apoptosis mainly by other signal pathways. Therefore, different structural modifications of 5-arylbenzofuran neolignan would induce apoptosis by regulation of different signal pathways.

\section{Experimental section}

\section{General methods and materials}

All the reagents were commercially available and used without further purification. Melting points were determined on an X-4 binocular microscope melting point apparatus. ${ }^{1} \mathrm{H}$ NMR and
A

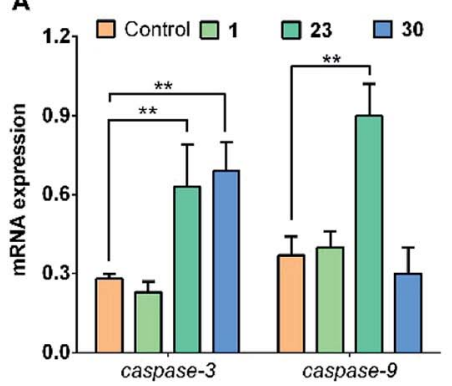

B

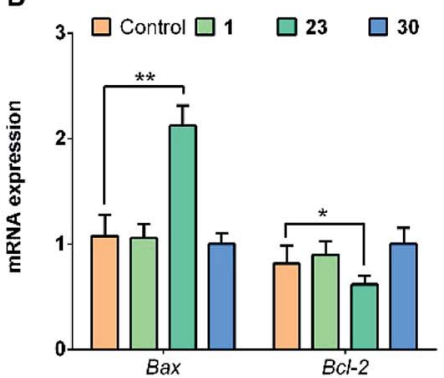

C

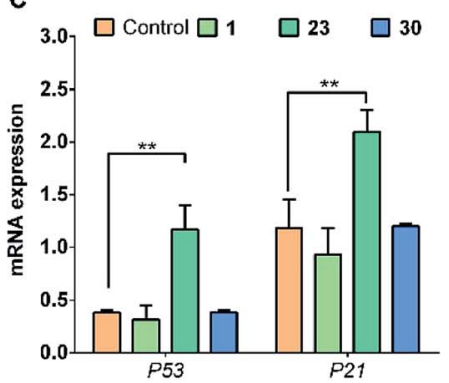

Fig. 4 mRNA expression levels of (A) caspase-3, caspase-9, (B) Bax, Bcl-2, (C) p53 and p21 in HepG2 cells treated with $20 \mu \mathrm{M}$ of different compounds $(1,23,30)$ for 24 h. $* P<0.05, * * P<0.01$. 
${ }^{13} \mathrm{C}$ NMR spectra were recorded on a Bruker AV-400 spectrometer, using tetramethylsilane (TMS) as the internal standard and chemical shifts $(\delta)$ were expressed in ppm. Mass spectra were obtained by an Agilent 1100 series LC-MS. Elemental analyses were performed on a Vario EL III (Germany) instrument.

\section{Synthesis of title compounds}

4-Allyl-2-(2-methylbenzofuran-5-yl)phenol (1). A mixture of honokiol $(10 \mathrm{mmol}), \mathrm{NaOAc}(1.0 \mathrm{mmol})$ and $\mathrm{PdCl}_{2}(0.15 \mathrm{mmol})$ in the co-solvent of DMA and $\mathrm{H}_{2} \mathrm{O}(35 \mathrm{~mL}, \mathrm{v} / \mathrm{v}=6: 1)$ was stirred under $\mathrm{O}_{2}(0.8 \mathrm{Mpa})$ at $60{ }^{\circ} \mathrm{C}$ for $16 \mathrm{~h}$. After cooling, the mixture was diluted with water and extracted with ethyl acetate. The combined extracts were dried over $\mathrm{Na}_{2} \mathrm{SO}_{4}$ and concentrated under reduced pressure. The residue was then purified by silica gel chromatography to afford $\mathbf{1}$ as light yellow oil $(86 \%) .{ }^{1} \mathrm{H}$ NMR (400 MHz, $\mathrm{CDCl}_{3}$ ), $\delta 7.53(\mathrm{~d}, J=1.5 \mathrm{~Hz}, 1 \mathrm{H}$, benzofuran 4 $\mathrm{H}), 7.50(\mathrm{~d}, J=8.4 \mathrm{~Hz}, 1 \mathrm{H}$, benzofuran $7 \mathrm{H}), 7.26(\mathrm{dd}, J=8.4$, $1.8 \mathrm{~Hz}, 1 \mathrm{H}$, benzofuran $6 \mathrm{H}), 7.10-7.07\left(\mathrm{~m}, 2 \mathrm{H}, \mathrm{C}_{6} \mathrm{H}_{3} 3,5 \mathrm{H}\right), 6.94$ $\left(\mathrm{d}, 1 \mathrm{H}, J=8.8 \mathrm{~Hz}, \mathrm{C}_{6} \mathrm{H}_{3} 6 \mathrm{H}\right), 6.41(\mathrm{~s}, 1 \mathrm{H}$, benzofuran $3 \mathrm{H}), 6.04-$ $5.93\left(\mathrm{~m}, 1 \mathrm{H}, \mathrm{CH}_{2} \mathrm{CH}=\mathrm{CH}_{2}\right), 5.21(\mathrm{~s}, 1 \mathrm{H}, \mathrm{OH}), 5.09(\mathrm{dd}, J=23.1$, $\left.5.9 \mathrm{~Hz}, 2 \mathrm{H}, \mathrm{CH}_{2} \mathrm{CH}=\mathrm{CH}_{2}\right), 3.36\left(\mathrm{~d}, J=6.7 \mathrm{~Hz}, 2 \mathrm{H}, \underline{\mathrm{CH}}_{2} \mathrm{CH}=\right.$ $\mathrm{CH}_{2}$ ), 2.49 (s, 3H, $\left.\mathrm{CH}_{3}\right) ;{ }^{13} \mathrm{C}$ NMR (101 MHz, $\mathrm{CDCl}_{3}$ ), $\delta$ 156.58, 154.44, 151.10, 138.08, 132.29, 131.79, 130.83, 130.21, 129.00, 128.75, 124.43, 120.87, 115.98, 115.75, 111.34, 102.93, 39.61, 14.19. LC-MS, $m / z: 265.1[\mathrm{M}+\mathrm{H}]^{+}$. Elemental anal (\%) calcd for $\mathrm{C}_{18} \mathrm{H}_{16} \mathrm{O}_{2}$ : C 81.79, $\mathrm{H}$ 6.10; found: C 81.85, H 6.08.

4-Allyl-2-(2-methyl-2,3-dihydrobenzofuran-5-yl)phenol To a stirred solution of honokiol $(10 \mathrm{mmol})$ in 1,2-dichloroethane $(40 \mathrm{~mL})$ was added concentrated sulfuric acid (98\%, 0.2 $\mathrm{mL}$ ) dropwise at room temperature. Then the mixture was heated to $50{ }^{\circ} \mathrm{C}$ and stirred for $24 \mathrm{~h}$. After cooling, the solvent was evaporated under reduced pressure and the residue was then purified by silica gel chromatography to afford 2 as light yellow oil (12\%). ${ }^{1} \mathrm{H}$ NMR (400 MHz, $\left.\mathrm{CDCl}_{3}\right) \delta 7.22(\mathrm{~s}, 1 \mathrm{H}, \mathrm{Ar}-\mathrm{H})$, $7.17(\mathrm{~d}, J=8.1 \mathrm{~Hz}, 1 \mathrm{H}, \mathrm{Ar}-\mathrm{H}), 7.03-7.01$ (m, 2H, Ar-H), 6.87 (d, $=8.1 \mathrm{~Hz}, 1 \mathrm{H}, \mathrm{Ar}-\mathrm{H}), 6.82(\mathrm{~d}, J=8.1 \mathrm{~Hz}, 1 \mathrm{H}, \mathrm{Ar}-\mathrm{H}), 5.96(\mathrm{dt}, J=$ 16.6, $\left.6.9 \mathrm{~Hz}, 1 \mathrm{H}, \mathrm{CH}_{2} \mathrm{CH}=\mathrm{CH}_{2}\right), 5.26(\mathrm{~s}, 1 \mathrm{H}, \mathrm{OH}), 5.11-5.01(\mathrm{~m}$, $\left.2 \mathrm{H}, \mathrm{CH}_{2} \mathrm{CH}=\underline{\mathrm{CH}}_{2}\right), 4.99-4.91\left(\mathrm{~m}, 1 \mathrm{H}, \mathrm{CH}_{3} \underline{\mathrm{HCH}}_{2}\right), 3.36-3.29$ $\left(\mathrm{m}, 3 \mathrm{H}, \mathrm{CH}_{2} \mathrm{CH}=\mathrm{CH}_{2}\right.$ and $\left.\mathrm{CH}_{3} \mathrm{CHCH}_{2}\right), 2.83$ (dd, $J=15.5$, $\left.7.6 \mathrm{~Hz}, 1 \mathrm{H}, \mathrm{CH}_{3} \mathrm{CHCH}_{2}\right), 1.47$ (d, $J=6.2 \mathrm{~Hz}, 3 \mathrm{H}, \mathrm{CH}_{3} \mathrm{CHCH}_{2}$ ); ${ }^{13} \mathrm{C}$ NMR $\left(101 \mathrm{MHz}, \mathrm{CDCl}_{3}\right) \delta 159.36,150.92,137.88,132.18$, 130.38, 129.15, 128.96, 128.67, 128.33, 128.27, 125.95, 115.64, 115.60, 109.88, 80.11, 39.48, 37.10, 21.85. LC-MS, $m / z: 267.2[\mathrm{M}+$ $\mathrm{H}]^{+}$. Elemental anal (\%) calcd for $\mathrm{C}_{18} \mathrm{H}_{18} \mathrm{O}_{2}$ : C 81.17, H 6.81; found: C 81.20, H 6.83.

2-(2-Methylbenzofuran-5-yl)-4-propylphenol (3). To a stirred solution of $1(2.0 \mathrm{mmol})$ and $\mathrm{NiCl}_{2} \cdot 6 \mathrm{H}_{2} \mathrm{O}(2.0 \mathrm{mmol})$ in EtOH $(10 \mathrm{~mL})$ was added $\mathrm{NaBH}_{4}(10 \mathrm{mmol})$ in five portions over $15 \mathrm{~min}$ and kept stirring for $5 \mathrm{~min}$ at room temperature. Then the reaction was quenched with dilute hydrochloric acid and extracted with $\mathrm{CH}_{2} \mathrm{Cl}_{2}$. The combined extracts were dried over $\mathrm{Na}_{2} \mathrm{SO}_{4}$ and concentrated under reduced pressure. The residue was then purified by silica gel chromatography to afford 3 as light yellow oil (81\%). ${ }^{1} \mathrm{H}$ NMR $\left(400 \mathrm{MHz}, \mathrm{CDCl}_{3}\right) \delta 7.53(\mathrm{~s}, 1 \mathrm{H}$, benzofuran $4 \mathrm{H}$ ), $7.48(\mathrm{~d}, J=8.4 \mathrm{~Hz}, 1 \mathrm{H}$, benzofuran $7 \mathrm{H}), 7.26$ $(\mathrm{d}, J=8.4 \mathrm{~Hz}, 1 \mathrm{H}$, benzofuran $6 \mathrm{H}), 7.08-7.04\left(\mathrm{~m}, 2 \mathrm{H}, \mathrm{C}_{6} \mathrm{H}_{3} 4,6\right.$
$\mathrm{H}), 6.90\left(\mathrm{~d}, J=7.9 \mathrm{~Hz}, 1 \mathrm{H}, \mathrm{C}_{6} \mathrm{H}_{3} 3 \mathrm{H}\right), 6.39(\mathrm{~s}, 1 \mathrm{H}$, benzofuran 3 $\mathrm{H}), 5.17(\mathrm{~s}, 1 \mathrm{H}, \mathrm{OH}), 2.55\left(\mathrm{t}, J=7.6 \mathrm{~Hz}, 2 \mathrm{H}, \mathrm{CH}_{2} \mathrm{CH}_{2} \mathrm{CH}_{3}\right), 2.47$ (s, 3H, $\mathrm{CH}_{3}$ ), 1.69-1.59 (m, 2H, $\left.\mathrm{CH}_{2} \mathrm{CH}_{2} \mathrm{CH}_{3}\right), 0.95$ (t, J=7.3 Hz, $\left.3 \mathrm{H}, \mathrm{CH}_{2} \mathrm{CH}_{2} \mathrm{CH}_{3}\right) ;{ }^{13} \mathrm{C} \mathrm{NMR}\left(101 \mathrm{MHz}, \mathrm{CDCl}_{3}\right) \delta 156.60,154.34$, 150.53 , 134.86, 131.60, 130.44, 130.17, 128.77, 128.22, 124.24, $120.67,115.41,111.36,102.73$, 37.27, 24.85, 14.17, 13.90. LCMS, $m / z: 267.0[\mathrm{M}+\mathrm{H}]^{+}$. Elemental anal (\%) calcd for $\mathrm{C}_{18} \mathrm{H}_{18} \mathrm{O}_{2}$ : C 81.17, $\mathrm{H}$ 6.81; found: C 81.22, $\mathrm{H} 6.79$.

2-(2-Methyl-2,3-dihydrobenzofuran-5-yl)-4-propylphenol (4). A mixture of 1 (5.0 mmol) and $\mathrm{Pd} / \mathrm{C}(10 \%, 0.25 \mathrm{mmol})$ in $\mathrm{MeOH}$ $(20 \mathrm{~mL})$ was refluxed under $\mathrm{H}_{2}(1.5 \mathrm{MPa})$ for $5 \mathrm{~h}$. After cooling, the mixture was filtered and concentrated under reduced pressure. The residue was then purified by silica gel chromatography to afford 4 as light yellow oil (93\%). ${ }^{1} \mathrm{H}$ NMR (400 MHz, $\left.\mathrm{CDCl}_{3}\right) \delta 7.24(\mathrm{~s}, 1 \mathrm{H}, \mathrm{Ar}-\mathrm{H}), 7.19(\mathrm{~d}, J=8.1 \mathrm{~Hz}, 1 \mathrm{H}, \mathrm{Ar}-\mathrm{H}), 7.04-$ $6.98(\mathrm{~m}, 2 \mathrm{H}, \mathrm{Ar}-\mathrm{H}), 6.86(\mathrm{~d}, J=8.5 \mathrm{~Hz}, 1 \mathrm{H}, \mathrm{Ar}-\mathrm{H}), 6.83(\mathrm{~d}, J=$ $8.1 \mathrm{~Hz}, 1 \mathrm{H}, \mathrm{Ar}-\mathrm{H}), 5.28(\mathrm{~s}, 1 \mathrm{H}, \mathrm{OH}), 5.01-4.92\left(\mathrm{~m}, 1 \mathrm{H}, \mathrm{CH}_{3}-\right.$ $\left.\mathrm{C}_{\mathbf{H C H}}\right), 3.34\left(\mathrm{dd}, J=15.5,8.8 \mathrm{~Hz}, 1 \mathrm{H}, \mathrm{CH}_{3} \mathrm{CHC}_{2}\right), 2.85$ (dd, $J$ $\left.=15.6,7.7 \mathrm{~Hz}, 1 \mathrm{H}, \mathrm{CH}_{3} \mathrm{CHCH}_{2}\right), 2.53\left(\mathrm{t}, J=7.6 \mathrm{~Hz}, 2 \mathrm{H}, \mathrm{CH}_{3}-\right.$ $\mathrm{CH}_{2} \mathrm{CH}_{2}$ ), 1.67-1.58 (m, 2H, $\left.\mathrm{CH}_{3} \mathrm{C}_{2} \mathrm{CH}_{2}\right), 1.49$ (d, $J=6.2 \mathrm{~Hz}$, $3 \mathrm{H}, \mathrm{CH}_{3} \mathrm{CHCH}_{2}$ ), $0.94\left(\mathrm{t}, J=7.3 \mathrm{~Hz}, 3 \mathrm{H}, \mathrm{CH}_{3} \mathrm{CH}_{2} \mathrm{CH}_{2}\right) ;{ }^{13} \mathrm{C} \mathrm{NMR}$ $\left(101 \mathrm{MHz}, \mathrm{CDCl}_{3}\right) \delta 159.29,150.56,134.80,130.22,129.35$, 128.94, 128.47, 128.25, 127.99, 125.93, 115.39, 109.81, 80.06, 37.25, 37.11, 24.82, 21.83, 13.88. LC-MS, $m / z: 269.1[\mathrm{M}+\mathrm{H}]^{+}$. Elemental anal (\%) calcd for $\mathrm{C}_{18} \mathrm{H}_{20} \mathrm{O}_{2}$ : C 80.56, $\mathrm{H}$ 7.51; found: $\mathrm{C}$ 80.52, H 7.50 .

5-(5-Allyl-2-methoxyphenyl)-2-methylbenzofuran (5). To a stirred solution of $1(1.0 \mathrm{mmol})$ and $\mathrm{CH}_{3} \mathrm{I}(3.0 \mathrm{mmol})$ in DMF $(5 \mathrm{~mL})$ was added $\mathrm{KOH}(2 \mathrm{mmol})$. After $3 \mathrm{~h}$ at room temperature, the mixture was diluted with water and extracted with ethyl acetate. The combined extracts were dried over $\mathrm{Na}_{2} \mathrm{SO}_{4}$ and concentrated under reduced pressure. The residue was then purified by silica gel chromatography to afford 5 as light yellow oil (71\%). ${ }^{1} \mathrm{H}$ NMR $\left(400 \mathrm{MHz}, \mathrm{CDCl}_{3}\right) \delta 7.58(\mathrm{~s}, 1 \mathrm{H}$, benzofuran 4 $\mathrm{H}), 7.41(\mathrm{~d}, J=8.4 \mathrm{~Hz}, 1 \mathrm{H}$, benzofuran $7 \mathrm{H}), 7.35(\mathrm{~d}, J=8.5 \mathrm{~Hz}$, $1 \mathrm{H}$, benzofuran $6 \mathrm{H}), 7.16\left(\mathrm{~d}, J=1.8 \mathrm{~Hz}, 1 \mathrm{H}, \mathrm{C}_{6} \mathrm{H}_{3} 6 \mathrm{H}\right), 7.12(\mathrm{~d}, J$ $\left.=8.3 \mathrm{~Hz}, 1 \mathrm{H}, \mathrm{C}_{6} \mathrm{H}_{3} 4 \mathrm{H}\right), 6.91\left(\mathrm{~d}, J=8.3 \mathrm{~Hz}, 1 \mathrm{H}, \mathrm{C}_{6} \mathrm{H}_{3} 3 \mathrm{H}\right), 6.37$ (s, $1 \mathrm{H}$, benzofuran $3 \mathrm{H}$ ), 5.99 (ddt, $J=16.8,10.0,6.7 \mathrm{~Hz}, 1 \mathrm{H}$, $\left.\mathrm{CH}_{2} \mathrm{CH}=\mathrm{CH}_{2}\right), 5.13-5.03\left(\mathrm{~m}, 2 \mathrm{H}, \mathrm{CH}_{2} \mathrm{CH}=\mathrm{CH}_{2}\right), 3.78(\mathrm{~s}, 3 \mathrm{H}$, $\left.\mathrm{OCH}_{3}\right), 3.38\left(\mathrm{~d}, J=6.7 \mathrm{~Hz}, 2 \mathrm{H}, \mathrm{CH}_{2} \mathrm{CH}=\mathrm{CH}_{2}\right), 2.45\left(\mathrm{~s}, 3 \mathrm{H}, \mathrm{CH}_{3}\right)$; ${ }^{13} \mathrm{C}$ NMR $\left(101 \mathrm{MHz}, \mathrm{CDCl}_{3}\right) \delta 155.69,154.97,154.02,137.82$, 133.01, 132.26, 131.52, 131.21, 129.10, 128.06, 124.98, 121.04, 115.59, 111.37, 110.01, 102.78, 55.78, 39.46, 14.15. LC-MS, $m / z$ : $279.0[\mathrm{M}+\mathrm{H}]^{+}$. Elemental anal (\%) calcd for $\mathrm{C}_{19} \mathrm{H}_{18} \mathrm{O}_{2}: \mathrm{C} 81.99$, H 6.52; found: C 81.96, H 6.50.

2-Methyl-6-(2-methyl-2,3-dihydrobenzofuran-5-yl)-4propylphenol (6). A mixture of $20(2.0 \mathrm{mmol})$ and $\mathrm{Pd} / \mathrm{C}(10 \%, 0.1$ $\mathrm{mmol})$ in $\mathrm{MeOH}(10 \mathrm{~mL})$ was refluxed under $\mathrm{H}_{2}(1.5 \mathrm{Mpa})$ for $5 \mathrm{~h}$. After cooling, the mixture was filtered and concentrated under reduced pressure. The residue was then purified by silica gel chromatography to afford 6 as light yellow oil $(88 \%) .{ }^{1} \mathrm{H}$ NMR $\left(400 \mathrm{MHz}, \mathrm{CDCl}_{3}\right) \delta 7.22(\mathrm{~s}, 1 \mathrm{H}$, dihydrobenzofuran $4 \mathrm{H})$, $7.17(\mathrm{~d}, J=8.1 \mathrm{~Hz}, 1 \mathrm{H}$, dihydrobenzofuran $6 \mathrm{H}), 6.91(\mathrm{~s}, 1 \mathrm{H}, \mathrm{Ar}-$ $\mathrm{H}), 6.86-6.81(\mathrm{~m}, 2 \mathrm{H}, \mathrm{Ar}-\mathrm{H}), 5.12(\mathrm{~s}, 1 \mathrm{H}, \mathrm{OH}), 5.02-4.93(\mathrm{~m}, 1 \mathrm{H}$, $\mathrm{CH}_{3} \mathrm{CHCH}_{2}$ ), 3.35 (dd, $J=15.5,8.8 \mathrm{~Hz}, 1 \mathrm{H}, \mathrm{CH}_{3} \mathrm{CHCH}_{2}$ ), 2.86 (dd, $\left.J=15.5,7.6 \mathrm{~Hz}, 1 \mathrm{H}, \mathrm{CH}_{3} \mathrm{CHCH}_{2}\right), 2.50(\mathrm{t}, J=7.6 \mathrm{~Hz}, 2 \mathrm{H}$, $\mathrm{CH}_{3} \mathrm{CH}_{2} \mathrm{CH}_{2}$ ), 2.27 (s, 3H, $\mathrm{CH}_{3}$ ), 1.66-1.57 (m, 2H, $\mathrm{CH}_{3} \mathrm{CH}_{2} \mathrm{CH}_{2}$ ), 
$1.50\left(\mathrm{~d}, J=6.1 \mathrm{~Hz}, 3 \mathrm{H}, \mathrm{CH}_{3} \mathrm{CHCH}_{2}\right), 0.94(\mathrm{t}, J=7.2 \mathrm{~Hz}, 3 \mathrm{H}$, $\mathrm{CH}_{3} \mathrm{CH}_{2} \mathrm{CH}_{2}$ ); ${ }^{13} \mathrm{C} \mathrm{NMR}\left(101 \mathrm{MHz}, \mathrm{CDCl}_{3}\right) \delta 159.35,148.66$, 134.17, 130.08, 129.42, 128.95, 128.40, 127.64, 127.50, 125.97, 124.06, 109.90, 80.04, 37.27, 37.10, 24.86, 21.82, 16.25, 13.93. LC-MS, $m / z: 283.1[\mathrm{M}+\mathrm{H}]^{+}$. Elemental anal (\%) calcd for $\mathrm{C}_{19} \mathrm{H}_{22} \mathrm{O}_{2}$ : C 80.82, $\mathrm{H} 7.85$; found: $\mathrm{C} 80.87, \mathrm{H} 7.84$.

4-Allyl-2-bromo-6-(2-methylbenzofuran-5-yl)phenol (7). To a stirred solution of $1(1.0 \mathrm{mmol})$ in $\mathrm{MeCN}(10 \mathrm{~mL})$ was added NBS $(1.0 \mathrm{mmol})$ in five portions over $1 \mathrm{~h}$ and kept stirring for $15 \mathrm{~min}$ at room temperature. Then the mixture was diluted with water and extracted with $\mathrm{CH}_{2} \mathrm{Cl}_{2}$. The combined extracts were dried over $\mathrm{Na}_{2} \mathrm{SO}_{4}$ and concentrated under reduced pressure. The residue was then purified by silica gel chromatography to afford 7 as light yellow oil (30\%). ${ }^{1} \mathrm{H}$ NMR (400 $\mathrm{MHz}, \mathrm{CDCl}_{3}$ ) $\delta 7.58(\mathrm{~s}, 1 \mathrm{H}$, benzofuran $4 \mathrm{H}), 7.46(\mathrm{~d}, J=8.4 \mathrm{~Hz}, 1 \mathrm{H}$, benzofuran $7 \mathrm{H}), 7.33-7.29(\mathrm{~m}, 2 \mathrm{H}, \mathrm{Ar}-\mathrm{H}), 7.08(\mathrm{~s}, 1 \mathrm{H}, \mathrm{Ar}-\mathrm{H}), 6.40(\mathrm{~s}$, $1 \mathrm{H}$, benzofuran $3 \mathrm{H}), 6.01-5.89\left(\mathrm{~m}, 1 \mathrm{H}, \mathrm{CH}_{2} \mathrm{CH}=\mathrm{CH}_{2}\right), 5.59(\mathrm{~s}$, $1 \mathrm{H}, \mathrm{OH}), 5.15-5.06\left(\mathrm{~m}, 2 \mathrm{H}, \mathrm{CH}_{2} \mathrm{CH}=\mathrm{CH}_{2}\right), 3.34(\mathrm{~d}, J=6.5 \mathrm{~Hz}$, $\left.2 \mathrm{H}, \mathrm{CH}_{2} \mathrm{CH}=\mathrm{CH}_{2}\right), 2.48\left(\mathrm{~s}, 3 \mathrm{H}, \mathrm{CH}_{3}\right) ;{ }^{13} \mathrm{C}$ NMR $(101 \mathrm{MHz}$, $\left.\mathrm{CDCl}_{3}\right) \delta 156.37,154.37,147.64,137.00,133.38,131.53,131.07$, 130.58, 129.90, 129.64, 124.33, 120.77, 116.26, 110.74, 110.57, 102.73, 39.07, 14.14. LC-MS, $m / z: 342.9[\mathrm{M}+\mathrm{H}]^{+}$. Elemental anal (\%) calcd for $\mathrm{C}_{18} \mathrm{H}_{15} \mathrm{O}_{2} \mathrm{Br}$ : $\mathrm{C} 62.99, \mathrm{H} 4.41$; found: $\mathrm{C} 63.03, \mathrm{H}$ 4.44.

4-Allyl-2-nitro-6-(2-methylbenzofuran-5-yl)phenol (8). To a stirred solution of $1(1.0 \mathrm{mmol})$ in the co-solvent of $\mathrm{CH}_{2} \mathrm{Cl}_{2}$ and acetic acid $(20 \mathrm{~mL}, \mathrm{v} / \mathrm{v}=1: 1)$ was added a solution of concentrated nitric acid $(65-68 \%, 4 \mathrm{mmol})$ in $5 \mathrm{~mL} \mathrm{CH}_{2} \mathrm{Cl}_{2}$ dropwise over $30 \mathrm{~min}$ in an ice bath and kept stirring for $30 \mathrm{~min}$ at room temperature. Then the reaction was quenched with water and extracted with $\mathrm{CH}_{2} \mathrm{Cl}_{2}$. The combined extracts were dried over $\mathrm{Na}_{2} \mathrm{SO}_{4}$ and concentrated under reduced pressure. The residue was then purified by silica gel chromatography to afford 8 as yellow oil (58\%). ${ }^{1} \mathrm{H}$ NMR $\left(400 \mathrm{MHz}, \mathrm{CDCl}_{3}\right) \delta 7.92(\mathrm{~s}$, $1 \mathrm{H}, \mathrm{Ar}-\mathrm{H}), 7.62(\mathrm{~s}, 1 \mathrm{H}$, benzofuran $4 \mathrm{H}), 7.49(\mathrm{~s}, 1 \mathrm{H}, \mathrm{Ar}-\mathrm{H}), 7.46$ $(\mathrm{d}, J=8.5 \mathrm{~Hz}, 1 \mathrm{H}$, benzofuran $7 \mathrm{H}), 7.35(\mathrm{~d}, J=8.4 \mathrm{~Hz}, 1 \mathrm{H}$, benzofuran $6 \mathrm{H}), 6.41(\mathrm{~s}, 1 \mathrm{H}$, benzofuran $3 \mathrm{H}), 5.95(\mathrm{dt}, J=16.6$, $\left.7.0 \mathrm{~Hz}, 1 \mathrm{H}, \mathrm{CH}_{2} \mathrm{CH}=\mathrm{CH}_{2}\right), 5.17-5.10\left(\mathrm{~m}, 2 \mathrm{H}, \mathrm{CH}_{2} \mathrm{CH}=\mathrm{CH}_{2}\right)$, $3.40\left(\mathrm{~d}, J=6.6 \mathrm{~Hz}, 2 \mathrm{H}, \mathrm{CH}_{2} \mathrm{CH}=\mathrm{CH}_{2}\right), 2.48\left(\mathrm{~s}, 3 \mathrm{H}, \mathrm{CH}_{3}\right) ;{ }^{13} \mathrm{C}$ NMR $\left(101 \mathrm{MHz}, \mathrm{CDCl}_{3}\right) \delta 156.34,154.50,151.41,139.41,136.04$, 133.88, 133.54, 131.78, 130.30, 129.38, 124.59, 123.08, 121.08, 117.17, 110.43, 102.74, 38.96, 14.14. LC-MS, $m / z: 310.0[\mathrm{M}+\mathrm{H}]^{+}$. Elemental anal (\%) calcd for $\mathrm{C}_{18} \mathrm{H}_{15} \mathrm{NO}_{4}$ : $\mathrm{C}$ 69.89, $\mathrm{H} 4.89, \mathrm{~N} 4.53$; found: C 69.94, H 4.90, N 4.51.

4-Allyl-2-nitroso-6-(2-methylbenzofuran-5-yl)phenol (9). To a stirred solution of $1(10 \mathrm{mmol})$ and $\mathrm{NaNO}_{2}(15 \mathrm{mmol})$ in the co-solvent of MeCN and $\mathrm{H}_{2} \mathrm{O}(30 \mathrm{~mL}, \mathrm{v} / \mathrm{v}=5: 1)$ was added concentrated hydrochloric acid (36-38\%, $3 \mathrm{~mL}$ ) over $1 \mathrm{~h}$ in an ice bath and kept stirring for $30 \mathrm{~min}$ at room temperature. Then the reaction was quenched with water and extracted with $\mathrm{CH}_{2} \mathrm{Cl}_{2}$. The combined extracts were dried over $\mathrm{Na}_{2} \mathrm{SO}_{4}$ and concentrated under reduced pressure. The residue was then purified by silica gel chromatography to afford $\mathbf{9}$ as a yellow powder (77\%). Mp 58-60 ${ }^{\circ} \mathrm{C} .{ }^{1} \mathrm{H} \mathrm{NMR}\left(400 \mathrm{MHz}, \mathrm{CDCl}_{3}\right) \delta 11.04$ (s, 1H, OH), 7.93 (d, $J=2.2 \mathrm{~Hz}, 1 \mathrm{H}, \mathrm{Ar}-\mathrm{H}), 7.63$ (d, $J=1.5 \mathrm{~Hz}$, $1 \mathrm{H}$, benzofuran $4 \mathrm{H}), 7.50(\mathrm{~d}, J=2.2 \mathrm{~Hz}, 1 \mathrm{H}, \mathrm{Ar}-\mathrm{H}), 7.47(\mathrm{~d}, J=$ $8.5 \mathrm{~Hz}, 1 \mathrm{H}$, benzofuran $7 \mathrm{H}), 7.36(\mathrm{dd}, J=8.5,1.8 \mathrm{~Hz}, 1 \mathrm{H}$, benzofuran $6 \mathrm{H}), 6.41(\mathrm{~s}, 1 \mathrm{H}$, benzofuran $3 \mathrm{H}$ ), 5.96 (ddt, $J=$ 17.2, 10.7, $\left.6.7 \mathrm{~Hz}, 1 \mathrm{H}, \mathrm{CH}_{2} \mathrm{CH}=\mathrm{CH}_{2}\right), 5.18-5.11(\mathrm{~m}, 2 \mathrm{H}$, $\left.\mathrm{CH}_{2} \mathrm{CH}=\mathrm{CH}_{2}\right), 3.41\left(\mathrm{~d}, J=6.6 \mathrm{~Hz}, 2 \mathrm{H}, \mathrm{CH}_{2} \mathrm{CH}=\mathrm{CH}_{2}\right), 2.48(\mathrm{~s}$, $\left.3 \mathrm{H}, \mathrm{CH}_{3}\right) ;{ }^{13} \mathrm{C}$ NMR $\left(101 \mathrm{MHz}, \mathrm{CDCl}_{3}\right) \delta 156.34,154.51,151.41$, 139.42, 136.07, 133.88, 133.53, 131.78, 130.31, 129.38, 124.61, 123.07, 121.10, 117.17, 110.43, 102.75, 38.96, 14.15. LC-MS, $m / z$ : $294.2[\mathrm{M}+\mathrm{H}]^{+}$. Elemental anal $(\%)$ calcd for $\mathrm{C}_{18} \mathrm{H}_{15} \mathrm{NO}_{3}$ : C 73.71, H 5.15, N 4.78; found: C 73.66, H 5.17, N 4.74.

4-Allyl-2-amino-6-(2-methylbenzofuran-5-yl)phenol (10). To a stirred solution of $9(5.0 \mathrm{mmol})$ and $\mathrm{NH}_{4} \mathrm{Cl}(1.0 \mathrm{mmol})$ in the co-solvent of EtOH, $\mathrm{H}_{2} \mathrm{O}$ and acetic acid $(62.5 \mathrm{~mL}, \mathrm{v} / \mathrm{v} / \mathrm{v}=$ $20: 4: 1)$ was added zinc dust $(25 \mathrm{mmol})$ in five portions over $30 \mathrm{~min}$ at room temperature. Then the mixture was filtered, diluted with water and extracted with ethyl acetate. The combined extracts were dried over $\mathrm{Na}_{2} \mathrm{SO}_{4}$ and concentrated under reduced pressure. The residue was then purified by silica gel chromatography to afford 10 as a brown powder $(73 \%)$. Mp 80-82 ${ }^{\circ} \mathrm{C}$. ${ }^{1} \mathrm{H}$ NMR $\left(400 \mathrm{MHz}\right.$, DMSO- $\left.d_{6}\right) \delta 7.56$ (s, $1 \mathrm{H}$, benzofuran $4 \mathrm{H}), 7.46(\mathrm{~d}, J=8.4 \mathrm{~Hz}, 1 \mathrm{H}$, benzofuran $7 \mathrm{H}), 7.29(\mathrm{~d}, J=$ $8.5 \mathrm{~Hz}, 1 \mathrm{H}$, benzofuran $6 \mathrm{H}), 6.58(\mathrm{~s}, 1 \mathrm{H}, \mathrm{Ar}-\mathrm{H}), 6.46(\mathrm{~s}, 1 \mathrm{H}, \mathrm{Ar}-$ $\mathrm{H}), 6.31(\mathrm{~s}, 1 \mathrm{H}$, benzofuran $3 \mathrm{H}), 5.98-5.87\left(\mathrm{~m}, 1 \mathrm{H}, \mathrm{CH}_{2} \mathrm{CH}=\right.$ $\mathrm{CH}_{2}$ ), 5.07 (d, $\left.J=17.0 \mathrm{~Hz}, 1 \mathrm{H}, \mathrm{CH}_{2} \mathrm{CH}=\mathrm{CH}_{2}\right), 5.00(\mathrm{~d}, J=$ $\left.10.0 \mathrm{~Hz}, 1 \mathrm{H}, \mathrm{CH}_{2} \mathrm{CH}=\mathrm{CH}_{2}\right), 4.72(\mathrm{br}, 1 \mathrm{H}), 3.20(\mathrm{~d}, J=6.7 \mathrm{~Hz}$, $\left.2 \mathrm{H}, \mathrm{CH}_{2} \mathrm{CH}=\mathrm{CH}_{2}\right), 2.45\left(\mathrm{~s}, 3 \mathrm{H}, \mathrm{CH}_{3}\right) ;{ }^{13} \mathrm{C} \mathrm{NMR}(101 \mathrm{MHz}$, DMSO- $\left.d_{6}\right) \delta$ 155.97, 153.57, 138.97, 138.87, 138.82, 134.47, 131.91, 130.42, 129.11, 125.16, 121.06, 118.96, 115.56, 114.34, 110.29, 103.34, 14.26. LC-MS, $m / z: 280.0[\mathrm{M}+\mathrm{H}]^{+}$. Elemental anal (\%) calcd for $\mathrm{C}_{18} \mathrm{H}_{17} \mathrm{NO}_{2}$ : $\mathrm{C} 77.40, \mathrm{H} \mathrm{6.13,} \mathrm{N} 5.01$; found: $\mathrm{C}$ 77.46, H 6.17, N 4.99 .

4-Allyl-2-(dimethylamino)-6-(2-methylbenzofuran-5-yl)phenol (11). To a solution of $10(1.0 \mathrm{mmol})$ and $\mathrm{CH}_{3} \mathrm{I}(3 \mathrm{mmol})$ in DMF $(5 \mathrm{~mL})$ was added NaOAc $(1.2 \mathrm{mmol})$. After reacting for $3 \mathrm{~h}$ at room temperature, the mixture was diluted with water and extracted with ethyl acetate. The combined extracts were dried over $\mathrm{Na}_{2} \mathrm{SO}_{4}$ and concentrated under reduced pressure. The residue was then purified by silica gel chromatography to afford 11 as red oil (71\%). ${ }^{1} \mathrm{H}$ NMR (400 $\left.\mathrm{MHz} \mathrm{CDCl}_{3}\right) \delta 7.69(\mathrm{~s}$, $1 \mathrm{H}$, benzofuran $4 \mathrm{H}), 7.47-7.41(\mathrm{~m}, 2 \mathrm{H}$, benzofuran $6,7 \mathrm{H}), 7.01$ (s, 1H, Ar-H), 6.99 (s, 1H, Ar-H), 6.39 (s, 1H, benzofuran $3 \mathrm{H}$ ), $5.99\left(\mathrm{dt}, J=16.6,7.4 \mathrm{~Hz}, 1 \mathrm{H}, \mathrm{CH}_{2} \mathrm{CH}=\mathrm{CH}_{2}\right), 5.14-5.04(\mathrm{~m}, 2 \mathrm{H}$, $\left.\mathrm{CH}_{2} \mathrm{CH}=\mathrm{CH}_{2}\right), 3.36\left(\mathrm{~d}, J=6.5 \mathrm{~Hz}, 2 \mathrm{H}, \mathrm{CH}_{2} \mathrm{CH}=\mathrm{CH}_{2}\right), 2.71(\mathrm{~s}$, $\left.6 \mathrm{H}, 2 \times \mathrm{CH}_{3}\right), 2.46\left(\mathrm{~s}, 3 \mathrm{H}, \mathrm{CH}_{3}\right) ;{ }^{13} \mathrm{C} \mathrm{NMR}\left(101 \mathrm{MHz}, \mathrm{CDCl}_{3}\right.$ ) $\delta 155.74,154.08,146.85,140.53,137.84,132.59,131.16,129.28$, $127.61,127.28,124.51,120.69,119.38,115.63,110.23,102.83$, 45.25, 39.86, 14.14. LC-MS, $m / z: 308.0[\mathrm{M}+\mathrm{H}]^{+}$. Elemental anal (\%) calcd for $\mathrm{C}_{20} \mathrm{H}_{21} \mathrm{NO}_{2}$ : C 78.15, $\mathrm{H}$ 6.89, $\mathrm{N}$ 4.56; found: $\mathrm{C} 78.11$, H 6.87, N 4.58.

$\mathrm{N}$-(5-Allyl-2-hydroxy-3-(2-methylbenzofuran-5-yl)phenyl)acetamide (12). To a mixture of $10(1.0 \mathrm{mmol})$ and $\mathrm{K}_{2} \mathrm{CO}_{3}(1.5$ $\mathrm{mmol})$ in ethyl acetate $(5 \mathrm{~mL})$ was added acetic anhydride (2 $\mathrm{mmol}$ ) dropwise over $10 \mathrm{~min}$ at room temperature. Then the reaction mixture was washed with hot water and the aqueous layer was extracted with ethyl acetate. The combined organic layer was dried over $\mathrm{Na}_{2} \mathrm{SO}_{4}$ and concentrated under reduced pressure. The residue was then purified by silica gel chromatography to afford 12 as a brown powder $(88 \%)$. Mp 70-72 ${ }^{\circ} \mathrm{C} .{ }^{1} \mathrm{H}$ NMR $\left(400 \mathrm{MHz}, \mathrm{CDCl}_{3}\right) \delta 7.85(\mathrm{br}, 1 \mathrm{H}), 7.55(\mathrm{~s}, 1 \mathrm{H}$, benzofuran 4 
$\mathrm{H}), 7.45(\mathrm{~d}, J=8.4 \mathrm{~Hz}, 1 \mathrm{H}$, benzofuran $7 \mathrm{H}), 7.40(\mathrm{~s}, 1 \mathrm{H}, \mathrm{Ar}-\mathrm{H})$, $7.29(\mathrm{~d}, J=8.3 \mathrm{~Hz}, 1 \mathrm{H}$, benzofuran $6 \mathrm{H}), 6.94(\mathrm{~s}, 1 \mathrm{H}, \mathrm{Ar}-\mathrm{H}), 6.38$ $(\mathrm{s}, 1 \mathrm{H}$, benzofuran $3 \mathrm{H}), 5.94\left(\mathrm{dt}, J=16.5,6.8 \mathrm{~Hz}, 1 \mathrm{H}, \mathrm{CH}_{2} \mathrm{CH}=\right.$ $\left.\mathrm{CH}_{2}\right), 5.11-5.02\left(\mathrm{~m}, 2 \mathrm{H}, \mathrm{CH}_{2} \mathrm{CH}=\mathrm{CH}_{2}\right), 3.32(\mathrm{~d}, J=6.3 \mathrm{~Hz}, 2 \mathrm{H}$, $\left.\mathrm{CH}_{2} \mathrm{CH}=\mathrm{CH}_{2}\right), 2.46\left(\mathrm{~s}, 3 \mathrm{H}, \mathrm{CH}_{3}\right), 2.20\left(\mathrm{~s}, 3 \mathrm{H}, \mathrm{COCH}_{3}\right) ;{ }^{13} \mathrm{C} \mathrm{NMR}$ $\left(101 \mathrm{MHz}, \mathrm{CDCl}_{3}\right) \delta 169.77,156.29,154.26,142.30,137.50$, 132.17, 131.91, 130.85, 129.72, 127.22, 126.25, 124.47, 120.87, 120.63, 115.84, 110.80, 102.74, 39.51, 24.19, 14.14. LC-MS, $m / z$ : $322.1[\mathrm{M}+\mathrm{H}]^{+}$. Elemental anal (\%) calcd for $\mathrm{C}_{20} \mathrm{H}_{19} \mathrm{NO}_{3}: \mathrm{C}$ 74.75, H 5.96, N 4.36; found: C 74.77, H 5.96, N 4.39.

$\mathrm{N}$-(5-Allyl-2-hydroxy-3-(2-methylbenzofuran-5-yl)phenyl)acrylamide (13). To a stirred mixture of $10(1.0 \mathrm{mmol})$ and $\mathrm{K}_{2} \mathrm{CO}_{3}(1.5 \mathrm{mmol})$ in $\mathrm{CH}_{2} \mathrm{Cl}_{2}(10 \mathrm{~mL})$ was added acryloyl chloride $(1.0 \mathrm{mmol})$ in $\mathrm{CH}_{2} \mathrm{Cl}_{2}(1.0 \mathrm{~mL})$ dropwise over $10 \mathrm{~min}$ at room temperature. Then the reaction was quenched with water and extracted with $\mathrm{CH}_{2} \mathrm{Cl}_{2}$. The combined organic layer was dried over $\mathrm{Na}_{2} \mathrm{SO}_{4}$ and concentrated under reduced pressure. The residue was then purified by silica gel chromatography to afford 13 as a yellow powder (46\%). Mp 64-66 ${ }^{\circ} \mathrm{C} .{ }^{1} \mathrm{H}$ NMR $(400$ $\left.\mathrm{MHz}, \mathrm{CDCl}_{3}\right) \delta 7.94(\mathrm{~s}, 1 \mathrm{H}), 7.58(\mathrm{~s}, 1 \mathrm{H}, \mathrm{Ar}-\mathrm{H}), 7.55(\mathrm{~d}, J=1.4 \mathrm{~Hz}$, $1 \mathrm{H}$, benzofuran $4 \mathrm{H}), 7.46(\mathrm{~d}, J=8.4 \mathrm{~Hz}, 1 \mathrm{H}$, benzofuran $7 \mathrm{H})$, $7.29(\mathrm{dd}, J=8.4,1.7 \mathrm{~Hz}, 1 \mathrm{H}$, benzofuran $6 \mathrm{H}), 7.15(\mathrm{~s}, 1 \mathrm{H}), 6.94$ $(\mathrm{s}, 1 \mathrm{H}, \mathrm{Ar}-\mathrm{H}), 6.44\left(\mathrm{~d}, J=16.2 \mathrm{~Hz}, 1 \mathrm{H}, \mathrm{COCH}=\mathrm{CH}_{2}\right), 6.39(\mathrm{~s}, 1 \mathrm{H}$, benzofuran $3 \mathrm{H}$ ), 6.31 (dd, $J=16.8,10.1 \mathrm{~Hz}, 1 \mathrm{H}, \mathrm{COCH}=\mathrm{CH}_{2}$ ), 5.95 (ddt, $J=16.8,10.0,6.7 \mathrm{~Hz}, 1 \mathrm{H}, \mathrm{CH}_{2} \mathrm{CH}=\mathrm{CH}_{2}$ ), 5.77 (d, $J=$ $\left.9.9 \mathrm{~Hz}, 1 \mathrm{H}, \mathrm{COCH}=\mathrm{CH}_{2}\right), 5.12-5.02\left(\mathrm{~m}, 2 \mathrm{H}, \mathrm{CH}_{2} \mathrm{CH}=\mathrm{CH}_{2}\right)$, $3.33\left(\mathrm{~d}, J=6.7 \mathrm{~Hz}, 2 \mathrm{H}, \mathrm{CH}_{2} \mathrm{CH}=\mathrm{CH}_{2}\right), 2.47\left(\mathrm{~s}, 3 \mathrm{H}, \mathrm{CH}_{3}\right) ;{ }^{13} \mathrm{C}$ NMR (101 MHz, $\mathrm{CDCl}_{3}$ ) $\delta 164.33,156.35,154.29,142.17,137.45$, 132.29, 131.71, 130.51, 129.80, 128.45, 127.21, 126.03, 124.39, 120.83, 120.64, 115.87, 110.90, 102.74, 39.56, 14.14. LC-MS, $m / z$ : $334.0[\mathrm{M}+\mathrm{H}]^{+}$. Elemental anal (\%) calcd for $\mathrm{C}_{21} \mathrm{H}_{19} \mathrm{NO}_{3}$ : C 75.66, H 5.74, N 4.20; found: C 75.60, H 5.76, N 4.19.

$\mathrm{N}$-(5-Allyl-2-hydroxy-3-(2-methylbenzofuran-5-yl)phenyl)-2chloroacetamide (14). The title compound was prepared from 10 and chloroacetyl chloride in a similar procedure described for 13. Purification by silica gel chromatography afforded 14 as a white powder (81\%). Mp 118-120 ${ }^{\circ} \mathrm{C}$. ${ }^{1} \mathrm{H}$ NMR $(400 \mathrm{MHz}$, $\left.\mathrm{CDCl}_{3}\right) \delta 8.81$ (brs, $\left.1 \mathrm{H}\right), 7.84(\mathrm{~s}, 1 \mathrm{H}, \mathrm{Ar}-\mathrm{H}), 7.53$ (s, 1H, benzofuran $4 \mathrm{H}), 7.49(\mathrm{~d}, J=8.3 \mathrm{~Hz}, 1 \mathrm{H}$, benzofuran $7 \mathrm{H}), 7.27(\mathrm{~d}, J=$ $6.3 \mathrm{~Hz}, 1 \mathrm{H}$, benzofuran $6 \mathrm{H}), 6.94(\mathrm{~s}, 1 \mathrm{H}, \mathrm{Ar}-\mathrm{H}), 6.41(\mathrm{~s}, 1 \mathrm{H}$, benzofuran $3 \mathrm{H}), 6.15(\mathrm{br}, 1 \mathrm{H}), 5.98(\mathrm{dt}, J=16.6,6.7 \mathrm{~Hz}, 1 \mathrm{H}$, $\left.\mathrm{CH}_{2} \mathrm{CH}=\mathrm{CH}_{2}\right), 5.14-5.05\left(\mathrm{~m}, 2 \mathrm{H}, \mathrm{CH}_{2} \mathrm{CH}=\mathrm{CH}_{2}\right), 4.22(\mathrm{~s}, 2 \mathrm{H}$, $\mathrm{COCH}_{2}$ ), 3.37 (d, $\left.J=6.3 \mathrm{~Hz}, 2 \mathrm{H}, \mathrm{CH}_{2} \mathrm{CH}=\mathrm{CH}_{2}\right), 2.49(\mathrm{~s}, 3 \mathrm{H}$, $\mathrm{CH}_{3}$ ); ${ }^{13} \mathrm{C}$ NMR $\left(101 \mathrm{MHz}, \mathrm{CDCl}_{3}\right) \delta$ 164.31, 156.72, 154.42, 141.21, 137.44, 132.57, 131.00, 130.13, 129.48, 126.82, 125.19, 124.13, 120.66, 119.98, 115.94, 111.34, 102.70, 43.01, 39.67, 14.19. LC-MS, $m / z: 356.0[\mathrm{M}+\mathrm{H}]^{+}$. Elemental anal (\%) calcd for $\mathrm{C}_{20} \mathrm{H}_{18} \mathrm{NO}_{3} \mathrm{Cl}$ : C 67.51, H 5.10, N 3.94; found: C 67.55, H 5.11, N 3.91 .

$\mathrm{N}$-(5-Allyl-2-hydroxy-3-(2-methylbenzofuran-5-yl)phenyl)-2(piperidin-1-yl)acetamide (15). A solution of $14(0.5 \mathrm{mmol})$, piperidine $(1.5 \mathrm{mmol})$ and triethylamine $(1.0 \mathrm{mmol})$ in THF (5 $\mathrm{mL}$ ) was stirred at room temperature for $8 \mathrm{~h}$. Then the mixture was concentrated under reduced pressure and purified by silica gel chromatography to afford 15 as a brown powder $(48 \%)$. Mp 125-127 ${ }^{\circ} \mathrm{C} .{ }^{1} \mathrm{H}$ NMR (400 MHz, DMSO- $\left.d_{6}\right) \delta 9.95(\mathrm{~s}, 1 \mathrm{H}), 8.80$ (br, 1H), $7.92(\mathrm{~s}, 1 \mathrm{H}, \mathrm{Ar}-\mathrm{H}), 7.61(\mathrm{~s}, 1 \mathrm{H}$, benzofuran $4 \mathrm{H}), 7.52$ (d,
$J=8.4 \mathrm{~Hz}, 1 \mathrm{H}$, benzofuran $7 \mathrm{H}), 7.32(\mathrm{~d}, J=8.4 \mathrm{~Hz}, 1 \mathrm{H}$, benzofuran $6 \mathrm{H}), 6.83(\mathrm{~s}, 1 \mathrm{H}, \mathrm{Ar}-\mathrm{H}), 6.61(\mathrm{~s}, 1 \mathrm{H}$, benzofuran 3 $\mathrm{H}), 5.96\left(\mathrm{dt}, J=16.7,6.8 \mathrm{~Hz}, 1 \mathrm{H}, \mathrm{CH}_{2} \mathrm{CH}=\mathrm{CH}_{2}\right), 5.10(\mathrm{~d}, J=$ $\left.17.0 \mathrm{~Hz}, 1 \mathrm{H}, \mathrm{CH}_{2} \mathrm{CH}=\mathrm{CH}_{2}\right), 5.04\left(\mathrm{~d}, J=9.9 \mathrm{~Hz}, 1 \mathrm{H}, \mathrm{CH}_{2} \mathrm{CH}=\right.$ $\left.\mathrm{CH}_{2}\right), 3.32\left(\mathrm{~d}, J=6.6 \mathrm{~Hz}, 2 \mathrm{H}, \mathrm{CH}_{2} \mathrm{CH}=\mathrm{CH}_{2}\right), 3.09(\mathrm{~s}, 2 \mathrm{H}$, $\left.\mathrm{COCH}_{2}\right), 2.51\left(\mathrm{~s}, 3 \mathrm{H}, \mathrm{CH}_{3}\right), 2.47(\mathrm{br}, 4 \mathrm{H}$, piperidine 2,6 H), 1.58 (br, $4 \mathrm{H}$, piperidine $3,5 \mathrm{H}), 1.41(\mathrm{~s}, 2 \mathrm{H}$, piperidine $4 \mathrm{H}) ;{ }^{13} \mathrm{C} \mathrm{NMR}$ $\left(101 \mathrm{MHz}, \mathrm{DMSO}-d_{6}\right) \delta 169.15,156.27,153.86,141.70,138.41$, 133.24, 132.13, 131.27, 129.36, 129.23, 125.81, 125.10, 121.23, 119.03, 116.07, 110.66, 103.36, 62.81, 54.63, 39.64, 26.19, 23.81, 14.25. LC-MS, $m / z: 405.1[\mathrm{M}+\mathrm{H}]^{+}$. Elemental anal (\%) calcd for $\mathrm{C}_{25} \mathrm{H}_{28} \mathrm{~N}_{2} \mathrm{O}_{3}$ : C 74.23, $\mathrm{H}$ 6.98, N 6.93; found: C 74.27, $\mathrm{H} 7.00, \mathrm{~N}$ 6.96 .

$N$-(5-Allyl-2-hydroxy-3-(2-methylbenzofuran-5-yl)phenyl)-2morpholinoacetamide (16). The title compound was prepared from 14 and morpholine in a similar procedure described for 15. Purification by silica gel chromatography afforded 16 as a light purple powder (85\%). Mp 147-149 ${ }^{\circ} \mathrm{C}$. ${ }^{1} \mathrm{H}$ NMR (400 MHz, DMSO- $\left.d_{6}\right) \delta 9.91(\mathrm{~s}, 1 \mathrm{H}), 8.82(\mathrm{~s}, 1 \mathrm{H}), 7.85(\mathrm{~s}, 1 \mathrm{H}, \mathrm{Ar}-\mathrm{H})$, $7.62(\mathrm{~s}, 1 \mathrm{H}$, benzofuran $4 \mathrm{H}), 7.52(\mathrm{~d}, J=8.4 \mathrm{~Hz}, 1 \mathrm{H}$, benzofuran $7 \mathrm{H}), 7.33(\mathrm{~d}, J=8.4 \mathrm{~Hz}, 1 \mathrm{H}$, benzofuran $6 \mathrm{H}), 6.86(\mathrm{~s}, 1 \mathrm{H}, \mathrm{Ar}-\mathrm{H})$, $6.61(\mathrm{~s}, 1 \mathrm{H}$, benzofuran $3 \mathrm{H}), 5.96(\mathrm{dt}, J=16.6,6.8 \mathrm{~Hz}, 1 \mathrm{H}$, $\mathrm{CH}_{2} \mathrm{CH}=\mathrm{CH}_{2}$ ), 5.11 (d, $\left.J=17.0 \mathrm{~Hz}, 1 \mathrm{H}, \mathrm{CH}_{2} \mathrm{CH}=\mathrm{CH}_{2}\right), 5.05$ (d, $\left.J=10.0 \mathrm{~Hz}, 1 \mathrm{H}, \mathrm{CH}_{2} \mathrm{CH}=\mathrm{CH}_{2}\right), 3.66(\mathrm{br}, 4 \mathrm{H}$, morpholine 2,6 H), $3.33\left(\mathrm{~d}, J=6.6 \mathrm{~Hz}, 2 \mathrm{H}, \mathrm{CH}_{2} \mathrm{CH}=\mathrm{CH}_{2}\right), 3.18\left(\mathrm{~s}, 2 \mathrm{H}, \mathrm{COCH}_{2}\right), 2.56$ (br, 4H, morpholine 3,5 H), $2.47\left(\mathrm{~s}, 3 \mathrm{H}, \mathrm{CH}_{3}\right) ;{ }^{13} \mathrm{C}$ NMR (101 MHz, DMSO- $\left.d_{6}\right) \delta 168.66,156.29,153.86,142.04,138.38,133.23$, $132.13,131.37,129.35,128.99,126.11,125.11,121.24,119.54$, 116.10, 110.65, 103.36, 66.77, 62.18, 53.63, 39.59, 14.24. LC-MS, $m / z: 407.1[\mathrm{M}+\mathrm{H}]^{+}$. Elemental anal (\%) calcd for $\mathrm{C}_{24} \mathrm{H}_{26} \mathrm{~N}_{2} \mathrm{O}_{4}: \mathrm{C}$ 70.92, H 6.45, N 6.89; found: C 70.90, H 6.49, N 6.86.

$\mathrm{N}$-(5-Allyl-2-hydroxy-3-(2-methylbenzofuran-5-yl)phenyl)-2(4-methylpiperazin-1-yl)acetamide (17). The title compound was prepared from 14 and 4-methylpiperazine in a similar procedure described for 15. Purification by silica gel chromatography afforded 17 as a brown powder (76\%). Mp 101-103 ${ }^{\circ} \mathrm{C}$. ${ }^{1} \mathrm{H}$ NMR (400 MHz, DMSO- $\left.d_{6}\right) \delta 9.86(\mathrm{~s}, 1 \mathrm{H}), 8.82$ (brs, 1H), 7.89 $(\mathrm{s}, 1 \mathrm{H}, \mathrm{Ar}-\mathrm{H}), 7.60(\mathrm{~s}, 1 \mathrm{H}$, benzofuran $4 \mathrm{H}), 7.51(\mathrm{~d}, J=8.4 \mathrm{~Hz}$, $1 \mathrm{H}$, benzofuran $7 \mathrm{H}), 7.31(\mathrm{~d}, J=8.4 \mathrm{~Hz}, 1 \mathrm{H}$, benzofuran $6 \mathrm{H})$, $6.82\left(\mathrm{~s}, 1 \mathrm{H}, \mathrm{C}_{6} \mathrm{H}_{2}, \mathrm{Ar}-\mathrm{H}\right), 6.61(\mathrm{~s}, 1 \mathrm{H}$, benzofuran $3 \mathrm{H}), 5.95(\mathrm{dt}, J$ $\left.=16.7,6.9 \mathrm{~Hz}, 1 \mathrm{H}, \mathrm{CH}_{2} \mathrm{CH}=\mathrm{CH}_{2}\right), 5.09(\mathrm{~d}, J=17.0 \mathrm{~Hz}, 1 \mathrm{H}$, $\mathrm{CH}_{2} \mathrm{CH}=\mathrm{CH}_{2}$ ), $5.03\left(\mathrm{~d}, J=10.0 \mathrm{~Hz}, 1 \mathrm{H}, \mathrm{CH}_{2} \mathrm{CH}=\mathrm{CH}_{2}\right), 3.31$ (d, $\left.J=6.6 \mathrm{~Hz}, 2 \mathrm{H}, \mathrm{CH}_{2} \mathrm{CH}=\mathrm{CH}_{2}\right), 3.14\left(\mathrm{~s}, 2 \mathrm{H}, \mathrm{COCH}_{2}\right), 2.54(\mathrm{br}, 4 \mathrm{H}$, piperazine- $\mathrm{H}$ ), 2.47 (s, 3H, $\mathrm{CH}_{3}$ ), 2.40 (brs, $4 \mathrm{H}$, piperazine- $\mathrm{H}$ ), $2.17\left(\mathrm{~s}, 3 \mathrm{H}, \mathrm{NCH}_{3}\right) ;{ }^{13} \mathrm{C}$ NMR (101 MHz, DMSO- $\left.d_{6}\right) \delta 168.79$, 156.27, 153.86, 141.81, 138.42, 133.26, 132.07, 131.29, 129.35, 129.16, 125.89, 125.12, 121.25, 119.15, 116.07, 110.65, 103.37, 61.93, 55.19, 53.16, 46.09, 39.62, 14.26. LC-MS, $m / z: 420.2[\mathrm{M}+$ $\mathrm{H}]^{+}$. Elemental anal (\%) calcd for $\mathrm{C}_{25} \mathrm{H}_{29} \mathrm{~N}_{3} \mathrm{O}_{3}: \mathrm{C} 71.57, \mathrm{H} \mathrm{6.97,} \mathrm{N}$ 10.02; found: C 71.55, H 6.99, N 10.05.

$N$-(5-Allyl-2-hydroxy-3-(2-methylbenzofuran-5-yl)phenyl)-2(4-phenylpiperazin-1-yl)acetamide (18). The title compound was prepared from 14 and 4-phenylpiperazine in a similar procedure described for 15. Purification by silica gel chromatography afforded 18 as a light purple powder (79\%). Mp $136-138{ }^{\circ} \mathrm{C} .{ }^{1} \mathrm{H}$ NMR (400 MHz, DMSO- $\left.d_{6}\right) \delta 9.98(\mathrm{~s}, 1 \mathrm{H}), 8.81(\mathrm{~s}, 1 \mathrm{H}), 7.92(\mathrm{~s}$, $1 \mathrm{H}, \mathrm{Ar}-\mathrm{H}), 7.60(\mathrm{~s}, 1 \mathrm{H}$, benzofuran $4 \mathrm{H}), 7.50(\mathrm{~d}, J=8.4 \mathrm{~Hz}, 1 \mathrm{H}$, 
benzofuran $7 \mathrm{H}), 7.31(\mathrm{~d}, J=8.4 \mathrm{~Hz}, 1 \mathrm{H}$, benzofuran $6 \mathrm{H}), 7.24-$ $7.17\left(\mathrm{~m}, 2 \mathrm{H}, \mathrm{C}_{6} \mathrm{H}_{5} 3,5 \mathrm{H}\right), 6.94\left(\mathrm{~d}, J=7.9 \mathrm{~Hz}, 2 \mathrm{H}, \mathrm{C}_{6} \mathrm{H}_{5} 2,6 \mathrm{H}\right)$, $6.84(\mathrm{~s}, 1 \mathrm{H}, \mathrm{Ar}-\mathrm{H}), 6.81-6.75\left(\mathrm{~m}, 1 \mathrm{H}, \mathrm{C}_{6} \mathrm{H}_{5} 4 \mathrm{H}\right), 6.58(\mathrm{~s}, 1 \mathrm{H}$, benzofuran $3 \mathrm{H}), 5.96\left(\mathrm{dt}, J=16.7,6.6 \mathrm{~Hz}, 1 \mathrm{H}, \mathrm{CH}_{2} \mathrm{CH}=\mathrm{CH}_{2}\right)$, $5.10\left(\mathrm{~d}, J=16.7 \mathrm{~Hz}, 1 \mathrm{H}, \mathrm{CH}_{2} \mathrm{CH}=\mathrm{CH}_{2}\right), 5.04(\mathrm{~d}, J=9.9 \mathrm{~Hz}, 1 \mathrm{H}$, $\left.\mathrm{CH}_{2} \mathrm{CH}=\mathrm{CH}_{2}\right), 3.32\left(\mathrm{~d}, J=6.6 \mathrm{~Hz}, 2 \mathrm{H}, \underline{\mathrm{CH}}_{2} \mathrm{CH}=\mathrm{CH}_{2}\right), 3.23(\mathrm{~s}$, $2 \mathrm{H}, \mathrm{COCH}_{2}$ ), 3.20 (br, $4 \mathrm{H}$, piperazine- $\mathrm{H}$ ), 2.70 (br, $4 \mathrm{H}$, piperazin$\mathrm{H}), 2.45\left(\mathrm{~s}, 3 \mathrm{H}, \mathrm{CH}_{3}\right) ;{ }^{13} \mathrm{C}$ NMR $\left(101 \mathrm{MHz}, \mathrm{DMSO}-d_{6}\right) \delta 168.72$, 156.26, 153.87, 151.43, 141.86, 138.42, 133.22, 132.11, 131.23, 129.39, 129.13, 125.94, 125.10, 121.24, 119.43, 119.19, 116.09, 115.94, 110.66, 103.37, 61.84, 53.19, 48.92, 39.65, 14.26. LC-MS, $m / z: 482.1[\mathrm{M}+\mathrm{H}]^{+}$. Elemental anal (\%) calcd for $\mathrm{C}_{30} \mathrm{H}_{31} \mathrm{~N}_{3} \mathrm{O}_{3}: \mathrm{C}$ 74.82, H 6.49, N 8.73; found: C 74.88, H 6.50, N 8.75.

(E)-4-Allyl-2-(benzylideneamino)-6-(2-methylbenzofuran-5yl)phenol (19). A mixture of 10 (1.0 mmol), benzaldehyde (1.0 $\mathrm{mmol})$ and acetic acid $(0.1 \mathrm{~mL})$ in EtOH $(10 \mathrm{~mL})$ was stirred at room temperature for $30 \mathrm{~min}$. The reaction was left overnight until precipitation. The precipitate was separated by filtration, washed with EtOH and dried to afford 19 as a yellow powder (68\%). Mp 91-93 ${ }^{\circ} \mathrm{C} .{ }^{1} \mathrm{H}$ NMR (400 MHz, DMSO- $\left.d_{6}\right) \delta 8.86(\mathrm{~s}, 1 \mathrm{H}$, $\mathrm{N}=\mathrm{CH}), 8.51(\mathrm{br}, 1 \mathrm{H}, \mathrm{OH}), 8.19-8.09(\mathrm{~m}, 2 \mathrm{H}, \mathrm{Ar}-\mathrm{H}), 7.71(\mathrm{~s}, 1 \mathrm{H}$, benzofuran $4 \mathrm{H}), 7.55-7.49(\mathrm{~m}, 4 \mathrm{H}, \mathrm{Ar}-\mathrm{H}), 7.44(\mathrm{~d}, J=8.6 \mathrm{~Hz}$, $1 \mathrm{H}$, benzofuran $6 \mathrm{H}$ ), 7.20 (s, 1H, Ar-H), 7.07 (s, 1H, Ar-H), 6.61 $(\mathrm{s}, 1 \mathrm{H}$, benzofuran $3 \mathrm{H}), 6.03\left(\mathrm{dt}, J=16.8,6.8 \mathrm{~Hz}, 1 \mathrm{H}, \mathrm{CH}_{2} \mathrm{CH}=\right.$ $\left.\mathrm{CH}_{2}\right), 5.14\left(\mathrm{~d}, J=17.0 \mathrm{~Hz}, 1 \mathrm{H}, \mathrm{CH}_{2} \mathrm{CH}=\mathrm{CH}_{2}\right), 5.06(\mathrm{~d}, J=9.8 \mathrm{~Hz}$, $\left.1 \mathrm{H}, \mathrm{CH}_{2} \mathrm{CH}=\mathrm{CH}_{2}\right), 3.38\left(\mathrm{~d}, J=6.6 \mathrm{~Hz}, 2 \mathrm{H}, \underline{\mathrm{CH}}_{2} \mathrm{CH}=\mathrm{CH}_{2}\right), 2.46$ $\left(\mathrm{s}, 3 \mathrm{H}, \mathrm{CH}_{3}\right) ;{ }^{13} \mathrm{C}$ NMR (101 MHz, DMSO- $\left.d_{6}\right) \delta$ 158.93, 156.21, 153.71, 147.78, 138.53, 137.44, 136.70, 133.26, 131.87, 131.15, 129.70, 129.16, 129.12, 128.95, 125.12, 121.13, 116.46, 116.10, 110.38, 103.35, 39.47, 14.27. LC-MS, $m / z: 368.0[\mathrm{M}+\mathrm{H}]^{+}$. Elemental anal (\%) calcd for $\mathrm{C}_{25} \mathrm{H}_{21} \mathrm{NO}_{2}$ : C 81.72, $\mathrm{H}$ 5.76, N 3.81; found: C 81.67, H 5.78, N 3.84.

4-Allyl-2-((dimethylamino)methyl)-6-(2-methylbenzofuran-5yl)phenol (20). A solution of 1 (2.0 $\mathrm{mmol})$, dimethylamine (aqueous solution, 40\%, $6.0 \mathrm{mmol}$ ) and formalin $(37 \%, 6.0$ $\mathrm{mmol})$ in $\mathrm{MeOH}(5.0 \mathrm{~mL})$ was stirred at $60^{\circ} \mathrm{C}$ for $6 \mathrm{~h}$. Then the mixture was concentrated under reduced pressure and purified by silica gel chromatography to afford 20 as light yellow oil (53\%). ${ }^{1} \mathrm{H} \mathrm{NMR}\left(400 \mathrm{MHz}, \mathrm{CDCl}_{3}\right) \delta 7.67(\mathrm{~s}, 1 \mathrm{H}$, benzofuran $4 \mathrm{H})$, 7.47-7.39 (m, 2H, benzofuran 6,7 H), $7.11(\mathrm{~s}, 1 \mathrm{H}, \mathrm{Ar}-\mathrm{H}), 6.78(\mathrm{~s}$, $1 \mathrm{H}, \mathrm{Ar}-\mathrm{H}), 6.37$ (s, 1H, benzofuran $3 \mathrm{H}), 6.05-5.92(\mathrm{~m}, 1 \mathrm{H}$, $\left.\mathrm{CH}_{2} \mathrm{CH}=\mathrm{CH}_{2}\right), 5.14-5.02\left(\mathrm{~m}, 2 \mathrm{H}, \mathrm{CH}_{2} \mathrm{CH}=\mathrm{CH}_{2}\right), 3.68(\mathrm{~s}, 2 \mathrm{H}$, $\mathrm{ArCH}_{2} \mathrm{~N}$ ), 3.33 (d, $\left.J=6.5 \mathrm{~Hz}, 2 \mathrm{H}, \underline{\mathrm{CH}}_{2} \mathrm{CH}=\mathrm{CH}_{2}\right), 2.45(\mathrm{~s}, 3 \mathrm{H}$, $\left.\mathrm{CH}_{3}\right), 2.33$ (s, 6H, N($\left.\left(\mathrm{CH}_{3}\right)_{2}\right) ;{ }^{13} \mathrm{C} \mathrm{NMR}\left(101 \mathrm{MHz}, \mathrm{CDCl}_{3}\right) \delta 155.52$, 153.97, 153.39, 138.04, 133.03, 130.20, 130.18, 129.19, 129.14, $127.40,124.83,122.06,120.92$, 115.44, 110.01, 102.84, 62.97, 44.35, 39.53, 14.15. LC-MS, $m / z: 322.1[\mathrm{M}+\mathrm{H}]^{+}$. Elemental anal (\%) calcd for $\mathrm{C}_{21} \mathrm{H}_{23} \mathrm{NO}_{2}$ : C 78.47, $\mathrm{H} 7.21, \mathrm{~N}$ 4.36; found: $\mathrm{C} 78.42$, H 7.19, N 4.38.

4-Allyl-2-(2-methylbenzofuran-5-yl)-6-(piperidin-1-ylmethyl) phenol (21). The title compound was prepared from 1 and piperidine in a similar procedure described for 20. Purification by silica gel chromatography afforded $\mathbf{2 1}$ as light yellow oil (81\%). ${ }^{1} \mathrm{H}$ NMR $\left(400 \mathrm{MHz}, \mathrm{CDCl}_{3}\right) \delta 7.66(\mathrm{~s}, 1 \mathrm{H}$, benzofuran $4 \mathrm{H})$, 7.44-7.41 (m, 2H, benzofuran 6,7 H), 7.09 (s, 1H, Ar-H), 6.78 (s, $1 \mathrm{H}, \mathrm{Ar}-\mathrm{H}), 6.38(\mathrm{~s}, 1 \mathrm{H}$, benzofuran $3 \mathrm{H}), 5.98(\mathrm{dt}, J=16.3$, $\left.8.0 \mathrm{~Hz}, 1 \mathrm{H}, \mathrm{CH}_{2} \mathrm{C} \underline{\mathrm{H}}=\mathrm{CH}_{2}\right), 5.12-5.02\left(\mathrm{~m}, 2 \mathrm{H}, \mathrm{CH}_{2} \mathrm{CH}=\mathrm{CH}_{2}\right)$, $3.70\left(\mathrm{~s}, 2 \mathrm{H}, \mathrm{ArCH}_{2} \mathrm{~N}\right), 3.33\left(\mathrm{~d}, J=6.5 \mathrm{~Hz}, 2 \mathrm{H}, \mathrm{CH}_{2} \mathrm{CH}=\mathrm{CH}_{2}\right)$, $2.52\left(\mathrm{br}, 4 \mathrm{H}\right.$, piperidine 2,6 H), $2.46\left(\mathrm{~s}, 3 \mathrm{H}, \mathrm{CH}_{3}\right), 1.61(\mathrm{br}, 4 \mathrm{H}$, piperidine 3,5 H), 1.47 (br, 2H, piperidine $4 \mathrm{H}$ ); ${ }^{13} \mathrm{C}$ NMR (101 $\left.\mathrm{MHz}, \mathrm{CDCl}_{3}\right) \delta 155.51,153.95,153.40,138.05,133.18,130.13$, 129.21, 129.15, 127.61, 127.55, 124.80, 121.87, 120.87, 115.40, 110.05, 102.85, 62.43, 53.87, 39.51, 25.66, 23.97, 14.14. LC-MS, $m / z: 362.1[\mathrm{M}+\mathrm{H}]^{+}$. Elemental anal (\%) calcd for $\mathrm{C}_{24} \mathrm{H}_{27} \mathrm{NO}_{2}$ : C 79.74, H 7.53, N 3.87; found: C 79.79, H 7.54, N 3.88.

4-Allyl-2-(2-methylbenzofuran-5-yl)-6-(morpholinomethyl)phenol (22). The title compound was prepared from 1 and morpholin in a similar procedure described for 20. Purification by silica gel chromatography afforded 22 as colourless oil (58\%). ${ }^{1} \mathrm{H}$ NMR $\left(400 \mathrm{MHz}, \mathrm{CDCl}_{3}\right) \delta 7.65(\mathrm{~s}, 1 \mathrm{H}$, benzofuran $4 \mathrm{H}), 7.45-$ $7.40(\mathrm{~m}, 2 \mathrm{H}$, benzofuran 6,7 H), $7.12(\mathrm{~s}, 1 \mathrm{H}, \mathrm{Ar}-\mathrm{H}), 6.81(\mathrm{~s}, 1 \mathrm{H}$, $\mathrm{Ar}-\mathrm{H}), 6.38(\mathrm{~s}, 1 \mathrm{H}$, benzofuran $3 \mathrm{H}), 5.97$ (dt, $J=16.7,6.8 \mathrm{~Hz}$, $\left.1 \mathrm{H}, \mathrm{CH}_{2} \mathrm{CH}=\mathrm{CH}_{2}\right), 5.13-5.03\left(\mathrm{~m}, 2 \mathrm{H}, \mathrm{CH}_{2} \mathrm{CH}=\mathrm{CH}_{2}\right), 3.74(\mathrm{~s}$, $2 \mathrm{H}, \mathrm{ArCH}_{2} \mathrm{~N}$ ), 3.72 (br, 4H, morpholine 2,6 H), 3.33 (d, $J=$ $6.6 \mathrm{~Hz}, 2 \mathrm{H}, \mathrm{CH}_{2} \mathrm{CH}=\mathrm{CH}_{2}$ ), $2.59(\mathrm{br}, 4 \mathrm{H}$, morpholine 3,5 H), 2.45 $\left(\mathrm{s}, 3 \mathrm{H}, \mathrm{CH}_{3}\right) ;{ }^{13} \mathrm{C}$ NMR $\left(101 \mathrm{MHz}, \mathrm{CDCl}_{3}\right) \delta 155.65,154.01$, 152.83 , 137.90, 132.92, 130.63, 130.57, 129.41, 129.20, 127.93, $124.77,120.91,120.88,115.56,110.11,102.83$, 66.69, 62.17, 52.90, 39.48, 14.15. LC-MS, $m / z: 364.1[\mathrm{M}+\mathrm{H}]^{+}$. Elemental anal (\%) calcd for $\mathrm{C}_{23} \mathrm{H}_{25} \mathrm{NO}_{3}$ : C 76.01, H 6.93, N 3.85; found: C 75.97, $\mathrm{H} 6.94, \mathrm{~N} 3.82$.

4-Allyl-2-(2-methylbenzofuran-5-yl)-6-((4-methylpiperazin-1yl)methyl)phenol (23). The title compound was prepared from 1 and 4-methylpiperazine in a similar procedure described for $\mathbf{2 0 .}$ Purification by silica gel chromatography afforded 23 as light yellow oil (68\%). ${ }^{1} \mathrm{H}$ NMR (400 $\left.\mathrm{MHz} \mathrm{CDCl}_{3}\right) \delta 7.65(\mathrm{~s}, 1 \mathrm{H}$, benzofuran $4 \mathrm{H}), 7.45-7.39(\mathrm{~m}, 2 \mathrm{H}$, benzofuran 6,7 $\mathrm{H}), 7.10(\mathrm{~s}$, $1 \mathrm{H}, \mathrm{Ar}-\mathrm{H}), 6.80(\mathrm{~s}, 1 \mathrm{H}, \mathrm{Ar}-\mathrm{H}), 6.38(\mathrm{~s}, 1 \mathrm{H}$, benzofuran $3 \mathrm{H}), 5.97$ $\left(\mathrm{dt}, J=16.6,7.7 \mathrm{~Hz}, 1 \mathrm{H}, \mathrm{CH}_{2} \mathrm{CH}=\mathrm{CH}_{2}\right), 5.29(\mathrm{br}, 1 \mathrm{H}, \mathrm{OH}), 5.12-$ $5.02\left(\mathrm{~m}, 2 \mathrm{H}, \mathrm{CH}_{2} \mathrm{CH}=\mathrm{CH}_{2}\right), 3.75\left(\mathrm{~s}, 2 \mathrm{H}, \operatorname{ArCH}_{2} \mathrm{~N}\right), 3.33(\mathrm{~d}, J=$ $\left.6.6 \mathrm{~Hz}, 2 \mathrm{H}, \mathrm{CH}_{2} \mathrm{CH}=\mathrm{CH}_{2}\right), 2.62(\mathrm{br}, 8 \mathrm{H}$, piperazine- $\mathrm{H}), 2.46(\mathrm{~s}$, $\left.3 \mathrm{H}, \mathrm{NCH}_{3}\right), 2.29\left(\mathrm{~s}, 3 \mathrm{H}, \mathrm{CH}_{3}\right) ;{ }^{13} \mathrm{C} \mathrm{NMR}\left(101 \mathrm{MHz}, \mathrm{CDCl}_{3}\right)$ $\delta 155.59,153.97,152.98,137.91,133.02,130.50,130.41,129.31$, 129.16, 127.78, 124.77, 121.32, 120.86, 115.52, 110.06, 102.82, $61.61,54.51,52.10,45.52,39.48,14.14$. LC-MS, $m / z: 377.1[\mathrm{M}+$ $\mathrm{H}]^{+}$. Elemental anal (\%) calcd for $\mathrm{C}_{24} \mathrm{H}_{28} \mathrm{~N}_{2} \mathrm{O}_{2}$ : C 76.56, $\mathrm{H} 7.50, \mathrm{~N}$ 7.44; found: C 76.55, $\mathrm{H} 7.47, \mathrm{~N} 7.48$.

4-Allyl-2-(2-methylbenzofuran-5-yl)-6-((4-phenylpiperazin-1yl)methyl)phenol (24). The title compound was prepared from 1 and 4-phenylpiperazine in a similar procedure described for $\mathbf{2 0 .}$ Purification by silica gel chromatography afforded 24 as a white powder (55\%). Mp 50-52 ${ }^{\circ} \mathrm{C} .{ }^{1} \mathrm{H}$ NMR (400 $\left.\mathrm{MHz}, \mathrm{CDCl}_{3}\right) \delta 7.67$ (s, $1 \mathrm{H}$, benzofuran $4 \mathrm{H}), 7.45-7.40(\mathrm{~m}, 2 \mathrm{H}, \mathrm{Ar}-\mathrm{H}), 7.27-7.21(\mathrm{~m}$, 2H, Ar-H), 7.23 (s, 1H, Ar-H), 6.92-6.81 (m, 4H, Ar-H), 6.37 (s, $1 \mathrm{H}$, benzofuran $3 \mathrm{H}), 5.98\left(\mathrm{dt}, J=16.4,6.7 \mathrm{~Hz}, 1 \mathrm{H}, \mathrm{CH}_{2} \mathrm{CH}=\right.$ $\mathrm{CH}_{2}$ ), 5.14-5.03 (m, $\left.2 \mathrm{H}, \mathrm{CH}_{2} \mathrm{CH}=\mathrm{CH}_{2}\right), 3.79\left(\mathrm{~s}, 2 \mathrm{H}, \mathrm{ArCH}_{2} \mathrm{~N}\right)$, $3.34\left(\mathrm{~d}, J=6.1 \mathrm{~Hz}, 2 \mathrm{H}, \mathrm{CH}_{2} \mathrm{CH}=\mathrm{CH}_{2}\right), 3.20$ (br, $4 \mathrm{H}$, piperazine$\mathrm{H}), 2.74$ (br, 4H, piperazine-H), $2.44\left(\mathrm{~s}, 3 \mathrm{H}, \mathrm{CH}_{3}\right) ;{ }^{13} \mathrm{C} \mathrm{NMR}(101$ $\left.\mathrm{MHz}, \mathrm{CDCl}_{3}\right) \delta 155.64,154.00,152.99,150.97,137.95,132.98$, $130.58,130.52$, 129.41, 129.21, 127.87, 124.81, 121.30, 120.92, $120.26,116.47,115.60,110.13,102.87,61.79,52.55,49.18$, 39.54, 14.20. LC-MS, $m / z: 439.1[\mathrm{M}+\mathrm{H}]^{+}$. Elemental anal (\%) calcd for $\mathrm{C}_{29} \mathrm{H}_{30} \mathrm{~N}_{2} \mathrm{O}_{2}$ : C 79.42, H 6.90, N 6.39; found: C 79.48, H $6.91, \mathrm{~N} 6.42$. 
6-Allyl-8-(2-methylbenzofuran-5-yl)-2H-benzo[b][1,4]-oxazin$3(4 \mathrm{H})$-one (25). To a stirred solution of 10 (1.0 mmol), triethylamine $(2.5 \mathrm{mmol})$ and 4-dimethylaminopyridine $(0.2 \mathrm{mmol})$ in THF ( $5 \mathrm{~mL}$ ) was added chloroacetyl chloride (1.0 mmol) in $\mathrm{CH}_{2} \mathrm{Cl}_{2}$ $(1.0 \mathrm{~mL})$ dropwise over $10 \mathrm{~min}$ at room temperature. Then the reaction was heated to reflux and stirred for $12 \mathrm{~h}$. After cooling, the mixture was concentrated under reduced pressure and purified by silica gel chromatography to afford 25 as a white powder $(44 \%)$. Mp 169-171 ${ }^{\circ} \mathrm{C} .{ }^{1} \mathrm{H}$ NMR (400 MHz, DMSO- $\left.d_{6}\right) \delta 10.72$ (s, $1 \mathrm{H}, \mathrm{NH}$ ), $7.62(\mathrm{~s}, 1 \mathrm{H}$, benzofuran $4 \mathrm{H}), 7.51(\mathrm{~d}, J=8.5 \mathrm{~Hz}, 1 \mathrm{H}$, benzofuran 7 $\mathrm{H}), 7.33(\mathrm{~d}, J=8.5 \mathrm{~Hz}, 1 \mathrm{H}$, benzofuran $6 \mathrm{H}), 6.84(\mathrm{~s}, 1 \mathrm{H}, \mathrm{Ar}-\mathrm{H}), 6.73$ $(\mathrm{s}, 1 \mathrm{H}, \mathrm{Ar}-\mathrm{H}), 6.60(\mathrm{~s}, 1 \mathrm{H}$, benzofuran $3 \mathrm{H}$ ), 5.95 (ddt, $J=16.5$, 9.5, $\left.6.7 \mathrm{~Hz}, 1 \mathrm{H}, \mathrm{CH}_{2} \mathrm{CH}=\mathrm{CH}_{2}\right), 5.12\left(\mathrm{~d}, J=17.2 \mathrm{~Hz}, 1 \mathrm{H}, \mathrm{CH}_{2} \mathrm{CH}=\right.$ $\mathrm{CH}_{2}$ ), 5.06 (d, $\left.J=9.9 \mathrm{~Hz}, 1 \mathrm{H}, \mathrm{CH}_{2} \mathrm{CH}=\mathrm{CH}_{2}\right), 4.54\left(\mathrm{~s}, 2 \mathrm{H}, \mathrm{OCH}_{2}\right)$, $3.33\left(\mathrm{~d}, J=6.7 \mathrm{~Hz}, 1 \mathrm{H}, \mathrm{CH}_{2} \mathrm{CH}=\mathrm{CH}_{2}\right), 2.46\left(\mathrm{~s}, 3 \mathrm{H}, \mathrm{CH}_{3}\right) ;{ }^{13} \mathrm{C} \mathrm{NMR}$ (101 MHz, DMSO- $d_{6}$ ) $\delta 165.89,156.43,153.93,139.24,138.07$, $134.40,131.93,130.32,129.25,128.52,125.01,124.86,121.14$, 116.42, 115.21, 110.55, 103.32, 67.32, 39.31, 14.25. LC-MS, $m / z$ : $320.0[\mathrm{M}+\mathrm{H}]^{+}$. Elemental anal (\%) calcd for $\mathrm{C}_{20} \mathrm{H}_{17} \mathrm{NO}_{3}$ : C 75.22, $\mathrm{H}$ 5.37, N 4.39; found: C 75.18, H 5.34, N 4.42.

6-Allyl-8-(2-methylbenzofuran-5-yl)-2H-benzo[b][1,4]-oxazine-2,3(4H)-dione (26). To a stirred solution of $10(1.0 \mathrm{mmol})$ and triethylamine $(2.5 \mathrm{mmol})$ in $\mathrm{CH}_{2} \mathrm{Cl}_{2}(10 \mathrm{~mL})$ was added oxalyl chloride $(1.5 \mathrm{mmol})$ in $\mathrm{CH}_{2} \mathrm{Cl}_{2}(1.0 \mathrm{~mL})$ dropwise over $10 \mathrm{~min}$ at room temperature. Then the reaction was quenched with water and extracted with $\mathrm{CH}_{2} \mathrm{Cl}_{2}$. The combined organic layer was dried over $\mathrm{Na}_{2} \mathrm{SO}_{4}$ and concentrated under reduced pressure. The residue was then purified by silica gel chromatography to afford 26 as a brown powder (42\%). Mp $160-162{ }^{\circ} \mathrm{C} .{ }^{1} \mathrm{H}$ NMR $(400 \mathrm{MHz}$, $\left.\mathrm{CDCl}_{3}\right) \delta 8.57(\mathrm{br}, 1 \mathrm{H}, \mathrm{NH}), 7.87(\mathrm{~s}, 1 \mathrm{H}$, benzofuran $4 \mathrm{H}), 7.58(\mathrm{~d}, J$ $=8.5 \mathrm{~Hz}, 1 \mathrm{H}$, benzofuran $7 \mathrm{H}), 7.48(\mathrm{~d}, J=8.5 \mathrm{~Hz}, 1 \mathrm{H}$, benzofuran $6 \mathrm{H}), 7.16(\mathrm{~s}, 1 \mathrm{H}, \mathrm{Ar}-\mathrm{H}), 6.86(\mathrm{~s}, 1 \mathrm{H}, \mathrm{Ar}-\mathrm{H}), 6.43(\mathrm{~s}, 1 \mathrm{H}$, benzofuran $3 \mathrm{H}), 6.04-5.93\left(\mathrm{~m}, 1 \mathrm{H}, \mathrm{CH}_{2} \mathrm{CH}=\mathrm{CH}_{2}\right), 5.17-5.10(\mathrm{~m}$, $\left.2 \mathrm{H}, \mathrm{CH}_{2} \mathrm{CH}=\mathrm{CH}_{2}\right), 3.45\left(\mathrm{~d}, J=6.6 \mathrm{~Hz}, 2 \mathrm{H}, \mathrm{CH}_{2} \mathrm{CH}=\mathrm{CH}_{2}\right), 2.49$ $\left(\mathrm{s}, 3 \mathrm{H}, \mathrm{CH}_{3}\right) ;{ }^{13} \mathrm{C} \mathrm{NMR}\left(101 \mathrm{MHz}, \mathrm{CDCl}_{3}\right) \delta 156.34,154.63,139.49$, 137.06, 136.76, 130.12, 129.70, 129.18, 124.66, 123.56, 122.68, 120.16, 116.35, 110.81, 108.82, 102.90, 40.16, 14.15. LC-MS, $m / z$ : $334.1[\mathrm{M}+\mathrm{H}]^{+}$. Elemental anal (\%) calcd for $\mathrm{C}_{20} \mathrm{H}_{15} \mathrm{NO}_{4}: \mathrm{C} 72.06$, $\mathrm{H}$ 4.54, N 4.20; found: C 72.11, H 4.56, N 4.15.

1-(4-Hydroxy-3-(2-methylbenzofuran-5-yl)phenyl)propan-2one (27). A mixture of $1(10 \mathrm{mmol})$ and $\mathrm{PdCl}_{2}(0.15 \mathrm{mmol})$ in the co-solvent of DMA and $\mathrm{H}_{2} \mathrm{O}(40 \mathrm{~mL}, \mathrm{v} / \mathrm{v}=4: 1)$ was stirred under $\mathrm{O}_{2}(0.8 \mathrm{Mpa})$ at $60{ }^{\circ} \mathrm{C}$ for $16 \mathrm{~h}$. After cooling, the mixture was diluted with water and extracted with ethyl acetate. The combined extracts were dried over $\mathrm{Na}_{2} \mathrm{SO}_{4}$ and concentrated under reduced pressure. The residue was then purified by silica gel chromatography to afford 27 as a white powder (64\%). Mp 118-120 ${ }^{\circ} \mathrm{C} .{ }^{1} \mathrm{H}$ NMR $\left(400 \mathrm{MHz}, \mathrm{CDCl}_{3}\right) \delta 7.53-7.48(\mathrm{~m}, 2 \mathrm{H}$, benzofuran 4,7 H), 7.26-7.24 (m, 1H, benzofuran $6 \mathrm{H}), 7.10-7.07$ $(\mathrm{m}, 2 \mathrm{H}, \operatorname{Ar}-\mathrm{H}), 6.97(\mathrm{~d}, 1 \mathrm{H}, J=7.8 \mathrm{~Hz}, \operatorname{Ar}-\mathrm{H}), 6.41(\mathrm{~s}, 1 \mathrm{H}$, benzofuran $3 \mathrm{H}), 5.35(\mathrm{br}, 1 \mathrm{H}, \mathrm{OH}), 3.66\left(\mathrm{~s}, 2 \mathrm{H}, \mathrm{CH}_{2}\right), 2.49(\mathrm{~s}$, $3 \mathrm{H}, \mathrm{CH}_{3}$ ), 2.18 (s, 3H, $\left.\mathrm{COCH}_{3}\right) ;{ }^{13} \mathrm{C} \mathrm{NMR} \mathrm{(101} \mathrm{MHz,} \mathrm{CDCl}_{3}$ ) $\delta 190.98,158.27,157.11,154.69,132.77,131.21,130.51,130.05$, 129.53, 129.28, 123.93, 120.69, 116.34, 111.78, 102.69, 50.17, 29.23, 14.17. LC-MS, $m / z: 280.9[\mathrm{M}+\mathrm{H}]^{+}$. Elemental anal (\%) calcd for $\mathrm{C}_{18} \mathrm{H}_{16} \mathrm{O}_{3}$ : C 77.12, $\mathrm{H}$ 5.75; found: $\mathrm{C} 77.07, \mathrm{H}$ 5.79.
(E/Z)-1-(4-Hydroxy-3-(2-methylbenzofuran-5-yl)phenyl)propan-2-one oxime (28). A mixture of 27 (2.0 mmol), hydroxylamine hydrochloride $(3.0 \mathrm{mmol})$ and NaOAc $(3.0 \mathrm{mmol})$ in EtOH $(20 \mathrm{~mL})$ was stirred and refluxed for $30 \mathrm{~min}$. After cooling, the mixture was diluted with water, shocked and placed until precipitation. Then the precipitate was separated by filtration, washed with water and dried to afford 28 as a white powder (95\%). Mp 38-40 ${ }^{\circ} \mathrm{C} .{ }^{1} \mathrm{H}$ NMR (400 MHz, $\left.\mathrm{CDCl}_{3}\right) \delta 7.52(\mathrm{~s}, 1 \mathrm{H}$, benzofuran $4 \mathrm{H}), 7.49(\mathrm{~d}, J=7.8 \mathrm{~Hz}, 1 \mathrm{H}$, benzofuran $7 \mathrm{H}), 7.27-$ $7.24(\mathrm{~m}, 1 \mathrm{H}$, benzofuran $6 \mathrm{H}), 7.13-7.09(\mathrm{~m}, 2 \mathrm{H}, \mathrm{Ar}-\mathrm{H}), 6.98-$ $6.90(\mathrm{~m}, 1 \mathrm{H}, \mathrm{Ar}-\mathrm{H}), 6.41$ (s, 1H, benzofuran $3 \mathrm{H}), 5.07(\mathrm{br}, 1 \mathrm{H}$, $\mathrm{OH}), 3.71(\mathrm{~s}, 1 \mathrm{H}, \mathrm{N}-\mathrm{OH}), 3.52-3.44\left(\mathrm{~m}, 2 \mathrm{H}, \mathrm{CH}_{2}\right), 2.49(\mathrm{~s}, 3 \mathrm{H}$, $\left.\mathrm{CH}_{3}\right), 1.86\left(\mathrm{~s}, 3 \mathrm{H}, \mathrm{CH}_{3}\right) ;{ }^{13} \mathrm{C} \mathrm{NMR}\left(101 \mathrm{MHz}, \mathrm{CDCl}_{3}\right) \delta 158.53$, $156.47,154.30,151.67,131.50,131.22$, 129.99, 129.23, 128.97, 128.56, 124.34, 120.78, 116.13, 111.13, 102.80, 41.21, 34.09, 19.64, 14.13, 13.45. LC-MS, $m / z: 296.1[\mathrm{M}+\mathrm{H}]^{+}$. Elemental anal (\%) calcd for $\mathrm{C}_{18} \mathrm{H}_{17} \mathrm{NO}_{3}$ : C 73.20, $\mathrm{H} 5.80, \mathrm{~N} 4.74$; found: $\mathrm{C} 73.17$, $\mathrm{H} 5.79, \mathrm{~N} 4.70$.

(E/Z)-2-(1-(4-Hydroxy-3-(2-methylbenzofuran-5-yl)phenyl)propan-2-ylidene)hydrazine-1-carbothioamide (29). A solution of $27(1.0 \mathrm{mmol})$, thiosemicarbazide $(4.0 \mathrm{mmol})$ and acetic acid $(0.2 \mathrm{~mL})$ in EtOH $(20 \mathrm{~mL})$ was stirred and refluxed for $1 \mathrm{~h}$. After cooling, the mixture was diluted with water, shocked and placed until precipitation. Then the precipitate was separated by filtration, washed with water and dried to afford 29 as a light yellow powder (57\%). Mp 97-99 ${ }^{\circ} \mathrm{C}^{1} \mathrm{H} \mathrm{NMR}(400 \mathrm{MHz}$, Acetone$\left.d_{6}\right) \delta 8.96$ (brs, 1H), 8.01 (brs, 1H), 7.58-6.75 (m, 8H), 6.37 (s, 1H, benzofuran $3 \mathrm{H}), 3.72-3.34\left(\mathrm{~m}, 2 \mathrm{H}, \mathrm{CH}_{2}\right), 2.31\left(\mathrm{~s}, 3 \mathrm{H}, \mathrm{CH}_{3}\right)$, 1.94-1.77 (m, 3H, $\left.\mathrm{CH}_{3}\right) ;{ }^{13} \mathrm{C}$ NMR (101 MHz, acetone- $\left.d_{6}\right)$ $\delta 180.10,155.88,153.92,152.99,152.21,133.13,131.51,129.23$, 129.04, 128.68, 128.35, 124.86, 120.95, 116.27, 109.86, 102.75, 43.98, 14.51, 13.11. LC-MS, $m / z: 354.0[\mathrm{M}+\mathrm{H}]^{+}$. Elemental anal (\%) calcd for $\mathrm{C}_{19} \mathrm{H}_{19} \mathrm{~N}_{3} \mathrm{O}_{3} \mathrm{~S}$ : C 64.57, $\mathrm{H} \mathrm{5.42,} \mathrm{N} 11.89$; found: $\mathrm{C}$ 64.61, H 5.44, N 11.85 .

(E/Z)- $N^{\prime}$-(1-(4-Hydroxy-3-(2-methylbenzofuran-5-yl)phenyl) propan-2-ylidene)benzohydrazide (30). A solution of $27(0.5$ $\mathrm{mmol})$, benzoylhydrazide $(1.0 \mathrm{mmol})$ and acetic acid $(0.2 \mathrm{~mL})$ in EtOH $(20 \mathrm{~mL})$ was stirred and refluxed for $1 \mathrm{~h}$. After cooling, the mixture was diluted with water, shocked and placed until precipitation. Then the precipitate was separated by filtration, washed with water and dried to afford $\mathbf{3 0}$ as a light yellow powder (90\%). Mp 99-101 ${ }^{\circ} \mathrm{C} .{ }^{1} \mathrm{H}$ NMR $\left(400 \mathrm{MHz}, \mathrm{CDCl}_{3}\right) \delta 7.87-$ $7.73(\mathrm{~m}, 2 \mathrm{H}, \mathrm{Ar}-\mathrm{H}), 7.53-7.44(\mathrm{~m}, 5 \mathrm{H}, \mathrm{Ar}-\mathrm{H}), 7.26-6.93(\mathrm{~m}, 4 \mathrm{H}$, $\mathrm{Ar}-\mathrm{H}), 6.40$ (s, $1 \mathrm{H}$, benzofuran $3 \mathrm{H}), 5.56(\mathrm{br}, 1 \mathrm{H}, \mathrm{OH}), 3.78-3.62$ $\left(\mathrm{m}, 2 \mathrm{H}, \mathrm{CH}_{2}\right), 2.48\left(\mathrm{~s}, 3 \mathrm{H}, \mathrm{CH}_{3}\right), 2.18\left(\mathrm{~s}, 1 \mathrm{H}, \mathrm{CH}_{3}\right), 1.88(\mathrm{~s}, 2 \mathrm{H}$, $\left.\mathrm{CH}_{3}\right) ;{ }^{13} \mathrm{C}$ NMR $\left(101 \mathrm{MHz}\right.$, acetone- $\left.d_{6}\right) \delta 164.42,156.78,155.00$, 154.08, 149.27, 135.21, 134.23, 133.62, 132.46, 131.36, 130.25, 129.95, 129.71, 129.41, 128.56, 127.66, 125.89, 121.97, 117.63, 117.36, 110.80, 103.76, 45.19, 15.91, 14.10. LC-MS, $m / z: 399.2[\mathrm{M}$ $+\mathrm{H}]^{+}$. Elemental anal (\%) calcd for $\mathrm{C}_{25} \mathrm{H}_{22} \mathrm{~N}_{2} \mathrm{O}_{3}: \mathrm{C} 75.36, \mathrm{H}$ 5.57, N 7.03; found: C 75.30, H 5.54, N 6.99.

2-(1-(4-Hydroxy-3-(2-methylbenzofuran-5-yl)phenyl)-propan2-yl)hydrazine-1-carbothioamide (31). To a stirred solution of 29 $(0.5 \mathrm{mmol})$ in EtOH $(5.0 \mathrm{~mL})$ was added $\mathrm{NaBH}_{4}(5.0 \mathrm{mmol})$ in five portions over $1 \mathrm{~h}$ and kept stirring for $1 \mathrm{~h}$ at room temperature. Then the reaction was quenched with dilute 
hydrochloric acid and extracted with $\mathrm{CH}_{2} \mathrm{Cl}_{2}$. The combined extracts were dried over $\mathrm{Na}_{2} \mathrm{SO}_{4}$ and concentrated under reduced pressure. The residue was then purified by silica gel chromatography to afford 31 as a white powder (31\%). Mp 81$83{ }^{\circ} \mathrm{C}^{1} \mathrm{H}$ NMR $\left(400 \mathrm{MHz}, \mathrm{DMSO}-d_{6}\right) \delta 9.30$ (brs, $\left.1 \mathrm{H}\right), 8.76$ (brs, 1H), 7.68 (brs, $1 \mathrm{H}), 7.65(\mathrm{~d}, J=1.0 \mathrm{~Hz}, 1 \mathrm{H}$, benzofuran $4 \mathrm{H}), 7.47$ $(\mathrm{d}, J=8.5 \mathrm{~Hz}, 1 \mathrm{H}$, benzofuran $7 \mathrm{H}), 7.38(\mathrm{dd}, J=8.5,1.3 \mathrm{~Hz}, 1 \mathrm{H}$, benzofuran $6 \mathrm{H}), 7.17(\mathrm{br}, 1 \mathrm{H}), 7.08\left(\mathrm{~d}, J=1.5 \mathrm{~Hz}, 1 \mathrm{H}, \mathrm{C}_{6} \mathrm{H}_{3} 2 \mathrm{H}\right)$, $6.95\left(\mathrm{dd}, J=8.2,1.6 \mathrm{~Hz}, 1 \mathrm{H}, \mathrm{C}_{6} \mathrm{H}_{3} 6 \mathrm{H}\right), 6.88$ (d, $J=8.1 \mathrm{~Hz}, 1 \mathrm{H}$, $\left.\mathrm{C}_{6} \mathrm{H}_{3} 5 \mathrm{H}\right), 6.58$ (s, 1H, benzofuran $3 \mathrm{H}$ ), 4.88 (br, 1H), 3.08-2.96 $(\mathrm{m}, 1 \mathrm{H}, \mathrm{CH}), 2.72\left(\mathrm{dd}, J=13.2,4.7 \mathrm{~Hz}, 1 \mathrm{H}, \mathrm{CH}_{2}\right), 2.44(\mathrm{~s}, 3 \mathrm{H}$, $\mathrm{CH}_{3}$ ), $2.32\left(\mathrm{dd}, J=13.1,8.7 \mathrm{~Hz}, 1 \mathrm{H}, \mathrm{CH}_{2}\right), 0.89(\mathrm{~d}, J=6.1 \mathrm{~Hz}, 3 \mathrm{H}$, $\left.\mathrm{CH}_{3}\right) ;{ }^{13} \mathrm{C}$ NMR (101 MHz, DMSO- $\left.d_{6}\right) \delta 181.88,156.04,153.55$, 152.87, 133.71, 131.81, 130.12, 129.16, 129.06, 128.36, 125.17, 121.10, 116.32, 110.23, 103.30, 57.09, 17.93, 14.24. LC-MS, $m / z$ : $356.0[\mathrm{M}+\mathrm{H}]^{+}$. Elemental anal (\%) calcd for $\mathrm{C}_{19} \mathrm{H}_{21} \mathrm{~N}_{3} \mathrm{O}_{2} \mathrm{~S}: \mathrm{C}$ 64.20, H 5.96, N 11.82; found: C 64.23, H 6.00, N 11.78.

$N^{\prime}$-(1-(4-Hydroxy-3-(2-methylbenzofuran-5-yl)phenyl)propan-2-yl)benzohydrazide (32). The title compound was prepared from 30 in a similar procedure described for $\mathbf{3 1}$. Purification by silica gel chromatography afforded 32 as a white powder (47\%). Mp 188-190 ${ }^{\circ} \mathrm{C} .{ }^{1} \mathrm{H}$ NMR $\left(400 \mathrm{MHz}, \mathrm{CDCl}_{3}\right) \delta 7.62$ (d, $J=7.5 \mathrm{~Hz}, \mathrm{C}_{6} \mathrm{H}_{5}$ 2,6 H), 7.49-7.45 (m, 3H, Ar-H), 7.43-7.38 $(\mathrm{m}, 2 \mathrm{H}$, benzofuran $4,7 \mathrm{H}), 7.22(\mathrm{~d}, J=8.5 \mathrm{~Hz}, 1 \mathrm{H}$, benzofuran 6 H), 7.15-7.11 (m, 2H, Ar-H), 6.95 (d, J=8.1 Hz, 1H, Ar-H), 6.39 (s, $1 \mathrm{H}$, benzofuran $3 \mathrm{H}), 5.26(\mathrm{br}, 2 \mathrm{H}), 3.45-3.35(\mathrm{~m}, 1 \mathrm{H}, \mathrm{CH})$, 2.81 (dd, $J=12.7,6.7 \mathrm{~Hz}, 1 \mathrm{H}, \mathrm{CH}_{2}$ ), 2.67 (dd, $J=13.0,6.6 \mathrm{~Hz}$, $1 \mathrm{H}, \mathrm{CH}_{2}$ ), $2.48\left(\mathrm{~s}, 3 \mathrm{H}, \mathrm{CH}_{3}\right), 1.16\left(\mathrm{~d}, J=6.0 \mathrm{~Hz}, 3 \mathrm{H}, \mathrm{CH}_{3}\right) ;{ }^{13} \mathrm{C}$ NMR (101 MHz, DMSO- $\left.d_{6}\right) \delta 166.06,156.07,153.55,152.74$, 133.72, 133.58, 131.92, 131.76, 130.19, 129.28, 129.07, 128.80, 128.24, 127.59, 125.19, 121.12, 116.21, 110.24, 103.31, 56.95, 40.80, 18.68, 14.22. LC-MS, $m / z: 401.2[\mathrm{M}+\mathrm{H}]^{+}$. Elemental anal (\%) calcd for $\mathrm{C}_{25} \mathrm{H}_{24} \mathrm{~N}_{2} \mathrm{O}_{3}$ : C 74.98, $\mathrm{H}$ 6.04, N 7.00; found: $\mathrm{C}$ 75.03, H 6.00, N 7.02.

\section{Biological assays}

Cell culture. The A549, K562, HepG2 and HUVEC cells were obtained from Institute of Cell Biology, Chinese Academy of Science (Shanghai China) and cultured in RPMI-1640 medium (Gibco; Thermo Fisher Scientific, Inc., Waltham, MA, USA) supplemented with $10 \%$ fetal bovine serum (Gibco; Thermo Fisher Scientific, Inc.) and $100 \mathrm{U} \mathrm{mL}^{-1}$ penicillin-streptomycin at $37{ }^{\circ} \mathrm{C}$ in incubator with $5 \% \mathrm{CO}_{2} / 95 \%$ air atmosphere.

Cytotoxicity assay. The cytotoxicity of all synthesized compounds were evaluated by typical MTT assay or MTS assay according to our previous method. ${ }^{33}$ The $\mathrm{IC}_{50}$ (the concentration required for $50 \%$ inhibition) was calculated by the Logit method.

Morphological analysis. The changes of cellular morphology were observed under an inverted fluorescence microscope. The HepG2 cells of experimental groups were treated with $20 \mu \mathrm{M}$ of different compounds (1, 23 and 30) for $24 \mathrm{~h}$, and the control group was treated with DMSO.

Hoechst 33258 staining. After treated with $20 \mu \mathrm{M}$ of different compounds (1, 23 and 30) for $24 \mathrm{~h}$, the cells were fixed with stationary liquid (24\% glacial acetic, $72 \%$ methyl alcohol, 4\% paraformaldehyde). Then the HepG2 cells were rinsed three times with PBS, each time for $5 \mathrm{~min}$, and then stained with a solution of Hoechst $33258\left(2 \mu \mathrm{g} \mathrm{mL}^{-1}\right)$ for $15 \mathrm{~min}$ at room temperature, and then washed with PBS again for three time, each time for $5 \mathrm{~min}$. Subsequently, the stained nuclei were observed under an inverted fluorescence microscope. The control group was treated with DMSO.

Flow cytometry analysis. The extent of apoptosis was quantitatively measured by an Annexin V-FITC/PI dual staining assay with annexin V-FITC/PI apoptosis detection Kit (Solarbio, CA1020). Briefly, HepG2 Cells were treated with $20 \mu \mathrm{M}$ of different compounds (1, 23 and 30) for $24 \mathrm{~h}$. Then detached and adherent cells were centrifuged at $1500 \times g$ for $5 \mathrm{~min}$, and then rinsed with ice-cold PBS for two times. Adjust the density of HepG2 cells to $5 \times 10^{5}$ cells per $\mathrm{mL}$. And the cells were subsequently stained with binding buffer for $10 \mathrm{~min}$ at $4{ }^{\circ} \mathrm{C}$, and labeled with Annexin V-fluorescein isothiocyanate (FITC) and propidium iodide. Sample were analyzed using a flow cytometer (BD Biosciences).

qRT-PCR assay. Total RNA was isolated from the HepG2 cells $\left(6 \times 6 \mathrm{~cm}, 2 \times 10^{6} /\right.$ well $)$ by using Trizol according to manufacturer's instructions and digested using DNase I (Takara) to remove the genomic DNA. The first-strand cDNA was synthesized using a cDNA synthesis kit (Fermentas, K1622). The mRNA expression levels of Bax, Bcl-2, caspase-3, caspase-9, p53 and $p 21$ were measured by qRT-PCR in the 96-well plates with the real-time detection PCR system (Bio-Rad, Shanghai, China) with SYBR Premix ExTaqII (Takara) and the gene $\beta$-actin was used as an endogenous control. The primers used for the qPCR analysis were as follows: $\mathrm{Bcl}-2$ forward, 5'-CAAAGGTGGATCAGATTCAAG-3'; $B c l$-2 reverse, 5'-GGTGAGCATTATCACCCAGAA3'; Bax forward, 5'-TGGCAGCAGTGACAGCAGCG-3'; Bax reverse, 5'-TACGGAGGTGGAGTGGGTGT-3'; caspase-3 forward, 5' AGAACACTGAAAACTCAGTGGATTC-3'; caspase-3 reverse, $5^{\prime}$ TCCATTTTATAACTG-TTGTCCAGGG-3'; caspase-9 forward, $5^{\prime}$ AGTCTATTTTATTATGGGCTCG-3'; caspase-9 reverse, ${ }^{\prime}$ ' TGGATGTTTATGTCACCTTTTC-3'; 221 forward, 5'-ATGGAGAACACTGAAAACTC- ${ }^{\prime} ; p 21$ reverse, $5^{\prime}$-TGTGAGCATGGAAACAATAC-3'; p53 forward, 5'-ACTCCCATTCTTCCACCTTTG- $3^{\prime}$, p53 reverse, $5^{\prime}$-CCCTGTTGCTGTAGCCATATT- $3^{\prime}$; $\beta$-actin forward, $5^{\prime}$ CCATAAACGATGCCGGA- $3^{\prime} ; \beta$-actin reverse, $5^{\prime}$-CACCACCCATAGAATCAAGA-3'.

\section{Conclusions}

In conclusion, a semi-synthesis methodology of 5-arylbenzofuran neolignans was developed. A series of 5-arylbenzofuran neolignan derivatives were synthesized and evaluated for their cytotoxicity in vitro against three tumor cell lines (HepG2, A549 and K562). Most derivatives revealed low cytotoxic effects and several compounds such as 23, 26 and $\mathbf{3 0}$ displayed obviously better cytotoxicity than the natural 5-arylbenzofuran neolignan 1. A preliminary structure-activity relationship was obtained, which showed that the modification of benzofuran, phenolic hydroxyl, allyl and the substituent on benzene ring made different effects on the cytotoxicity. For further understanding the anti-proliferative activities and mechanism of 5- 
arylbenzofuran neolignans, a series of biological assays were done around these compounds. As a result, compounds 23 and 30 could induce the apoptosis of HepG2 cells through regulation of different signal pathways. The selectivity assay for cytotoxicity showed tumor cells were more sensitive to the promising compounds than normal cells. In addition, a one-pot method of Waker-type cyclization and Wacker-type oxidation was developed, which may promote the synthesis of benzofuran ketones and related structures.

It's the first time for detailed research of 5-arylbenzofuran neolignans including semi-synthesis methodology, structural modification, cytotoxicity, structure-activity relationship and anti-proliferation mechanism after they were isolated from plants. The methods and conclusions in this paper would promote the research on 5-arylbenzofuran neolignan and its derivatives in the cancer therapy and other fields.

\section{Conflicts of interest}

The authors declare no competing interests.

\section{Acknowledgements}

This work was supported by the National Natural Science Foundation of China (No. 21442014).

\section{Notes and references}

1 S. Apers, A. Vlietinck and L. Pieters, Phytochem. Rev., 2003, 2, 201-217.

2 J. K. Kim and J. G. Jun, J. Cell. Biochem., 2011, 112, 38163823.

3 M. S. Setzer, K. G. Byler, I. V. Ogungbe and W. N. Setzer, Sci. Pharm., 2017, 85, 5-32.

4 T. Morikawa, I. Hachiman, K. Matsuo, E. Nishida, K. Ninomiya, T. Hayakawa, O. Yoshie, O. Muraoka and T. Nakayama, J. Nat. Prod., 2016, 79, 2005-2013.

5 L. F. L. Barros, A. Barison, M. J. Salvador, R. D. Mello-Silva, E. C. Cabral, M. N. Eberlin and M. E. A. Stefanello, J. Nat. Prod., 2009, 72, 1529-1532.

6 W. L. Kuo, C. Y. Chung, T. L. Hwang and J. J. Chen, Phytochemistry, 2013, 85, 153-160.

7 C. Y. Chung, W. L. Kuo, T. L. Hwang, M. I. Chung and J. J. Chen, Chem. Biodiversity, 2015, 12, 1263-1270.

8 J. Ping; J. Qi, H. M. Feng, and K. Misun, PCT Pat., WO2017083363, 2017.

9 A. X. Hu, D. Lin, K. M. Li, J. Ye, A. L. Liu and W. W. Lian, Chin. Pat., CN105622558B, 2016.

10 Z. B. Zhou, J. G. Luo, K. Pan, S. M. Shan, W. Zhang and L. Y. Kong, Planta Med., 2013, 79, 1730-1735.

11 T. Mitsudome, T. Umetani, N. Nosaka, K. Mori, T. Mizugaki, K. Ebitani and K. Kaneda, Angew. Chem., Int. Ed., 2006, 45, 481-485.

12 Q. Shen, Y. Dai, G. Wang, F. Yao, Y. Duan, H. Chen, W. Zhang, X. Zhang and X. Yao, Bioorg. Med. Chem., 2014, 22, 2671-2677.
13 Z. L. Kong, S. C. Tzeng and Y. C. Liu, Bioorg. Med. Chem. Lett., 2005, 15, 163-166.

14 N. C. Ulrich, J. G. Kodet, N. R. Mente, C. H. Kuder, J. A. Beutler, R. J. Hohl and D. F. Wiemer, Bioorg. Med. Chem., 2010, 18, 1676-1683.

15 T. Yamasaki, H. Hirose, T. Yamashita, N. Takakura, S. Morimoto, T. Nakahata, A. Kina, Y. Nakano, Y. O. Tamura, J. Sugama, T. Odani, Y. Shimizu, S. Iwasaki, M. Watanabe, T. Maekawa and S. Kasai, Bioorg. Med. Chem., 2017, 25, 4153-4162.

16 Y. Li, X. Qiang, L. Luo, X. Yang, G. Xiao, Y. Zheng, Z. Cao, Z. Sang, F. Su and Y. Deng, Bioorg. Med. Chem., 2017, 25, 714-726.

17 S. D. Tala, T. H. Ou, Y. W. Lin, K. S. Tala, S. H. Chao, M. H. Wu, T. H. Tsai, R. Kakadiya, S. Suman, C. H. Chen, T. C. Lee and T. L. Su, Eur. J. Med. Chem., 2014, 76, 155-169. 18 R. Bollu, J. D. Palem, R. Bantu, V. Guguloth, L. Nagarapu, S. Polepalli and N. Jain, Eur. J. Med. Chem., 2015, 89, 138146.

19 D. S. Xie, Y. C. Wang, J. Xie, J. Lu, J. J. Cui, M. Zhang, L. Fu and Y. X. Wang, Med. Chem. Res., 2014, 23, 4977-4989.

20 S. M. Cloonan, J. J. Keating, S. G. Butler, A. J. S. Knox, A. M. Jørgensen, G. H. Peters, D. Rai, D. Corrigan, D. G. Lloyd, D. C. Williams and M. J. Meegan, Eur. J. Med. Chem., 2009, 44, 4862-4888.

21 J. B. Liu, R. H. Cao, W. Yi, C. M. Ma, Y. Q. Wan, B. H Zhou, L. Ma and H. C. Song, Eur. J. Med. Chem., 2009, 44, 17731778.

22 G. T. Notte and J. L. Leighton, J. Am. Chem. Soc., 2008, 130, 6676-6677.

23 P. Thanigaimalai, K. C. Lee, V. K. Sharma, E. Roh, Y. Kim and S. H. Jung, Bioorg. Med. Chem. Lett., 2011, 21, 3527-3530.

24 D. S. Grant, T. L. Williams, M. Zahaczewsky and A. P. Dicker, Int. J. Cancer, 2003, 104, 121-129.

25 O. Meurette, A. Fontaine, A. Pebillard, G. L. Moigne, T. Lamy, D. Lagadic-Gossmann and M. T. Dimanche-Boitrel, Ann. N. Y. Acad. Sci., 2006, 1090, 209-216.

26 X. Zhao, S. Y. Kim and K. Y. Park, J. Med. Food, 2013, 16, 919.

27 G. Rodríguez-Berriguete, L. Galvis, B. Fraile, F. R. de Bethencourt, P. Martínez-Onsurbe, G. Olmedilla, R. Paniagua and M. Royuela, Hum. Pathol., 2012, 43, 229237.

28 Z. Sun, Q. Han, L. Duan, Q. Yuan and H. Wang, Oncol. Lett., 2018, 15, 1999-2005.

29 S. M. Woo, Y. K. Choi, A. J. Kim, S. G. Cho and S. G. Ko, Mol. Med. Rep., 2016, 13, 1091-1096.

30 G. Hollmann, R. Linden, A. Giangrande and S. Allodi, Aquat. Toxicol., 2016, 173, 1-8.

31 M. Moulin, S. Carpentier, T. Levade and A. P. Arrigo, Apoptosis, 2007, 12, 1703-1720.

32 A. Karimian, Y. Ahmadi and B. Yousefi, DNA Repair, 2016, 42, 63-71.

33 L. Wang, Q. Lin, T. Yang, Y. Liang, Y. Luo, Y. Nie, J. Shen, X. Fu, Y. Tang and F. Luo, J. Agric. Food Chem., 2017, 65, 8374-8385. 